STONE CENTER ON SOCIO-ECONOMIC INEQUALITY

WORKING PAPER SERIES

No. 47

Rural Poverty Reduction and Economic Transformation in China: A Decomposition Approach

\author{
Maria Ana Lugo \\ Chiyu Niu \\ Ruslan Yemtsov
}

November 2021

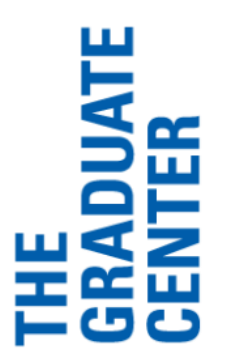




\title{
Rural Poverty Reduction and Economic Transformation in China: A Decomposition Approach ${ }^{1}$
}

\author{
Maria Ana Lugo, Chiyu Niu and Ruslan Yemtsov \\ The World Bank
}

November 17, 2021

\begin{abstract}
Rural poverty in China fell from 96 percent in 1980 to less than 1 percent of the population in 2019. Using PovcalNet data for China and a set of comparable countries, this paper estimates growth-poverty elasticities. It finds that China stands out for its record of sustained, fast growth, rather than because of an unusually high growth-poverty elasticity. In addition, changes in mean consumption, rather than changes in the distribution, drive poverty reduction. Furthermore, until 2010, changes in inequality attenuated the impact of growth on poverty. The paper also studies which channels mattered the most for rural poverty reduction by applying a decomposition framework to multiple rounds of Chinese Household Income Project surveys conducted in 1988, 1995, 2002, 2007, 2013, and 2018. The findings show that broad-based, labor-intensive growth in agriculture was initially the main driving force for rural poverty reduction, followed by the expansion of non-agriculture sectors. As the country's poverty rate approached 10 percent by 2007, transfers from migrant workers and, later, public transfers became the major drivers of further rural poverty reduction. Throughout the period, the fall in the demographic dependency rate also played a significant role. As China's living standards continue to rise, the official definition of poverty will have to adjust to the higher minimum. Continued structural transformation and the inclusive growth agenda retain crucial importance for sustained poverty reduction.

JEL Classification: D31, D63, I32, O15, O53.
\end{abstract}

Keywords: China, Rural poverty, economic transformation, growth elasticity of poverty, decomposition of poverty reduction, inequality, poverty line.

\footnotetext{
${ }^{1}$ This work was done under the guidance of Martin Raiser, Country Director for China and Mongolia, and Director for Korea, Hassan Zaman, EFI Regional Director for East Asia and the Pacific, and Rinku Murgai, Practice Manager. We are grateful for the insightful comments received throughout the preparation and review of this work from Samuel Freije-Rodriguez, Ruth Hill, Aart Kraay, Branko Milanovic, Ambar Narayan, Phillip O'Keefe, Martin Raiser, Gong Sen, and Xiaomin Liang. We also received useful comments from the participants of a technical workshop organized by the Center for International Knowledge on Development (CIKD) and the World Bank, held in March 2021. This work was done as part of the Advisory Services \& Analytics "Poverty Reduction in China: Insights for the World and the Way Ahead - (P172519)', Poverty and Equity Unit for East Asia and the Pacific, Maria Ana Lugo (co-TTL) and Ruslan Yemtsov (co-TTL).
} 


\section{Introduction}

China experienced a poverty reduction trend whose speed and size has global proportions. Between 1980 and 2019 , the proportion of people living in poverty -as per the official 2010 standard- fell from 96.2 to 0.6 percent of the rural population (Figure 1, left panel). ${ }^{2}$ The poverty headcount dropped from 765.4 million to 6 million people, that is nearly 750 million fewer poor people after four decades. In other words, on average, per year there were almost 20 million fewer poor people over 40 years (with an average decline of 2.5 percentage point per year). If one considers higher poverty lines, such as those typically used in lower-middle and upper-middle income countries (World Bank 2018), poverty in China declined rapidly and continuously as well - albeit more slowly than using the national standard (Figure 1, right panel).

Figure 1: Poverty reduction in China over the past 40 years based on the 2010 poverty standard (panel a) and based on international poverty lines (panel b), 1981-2019
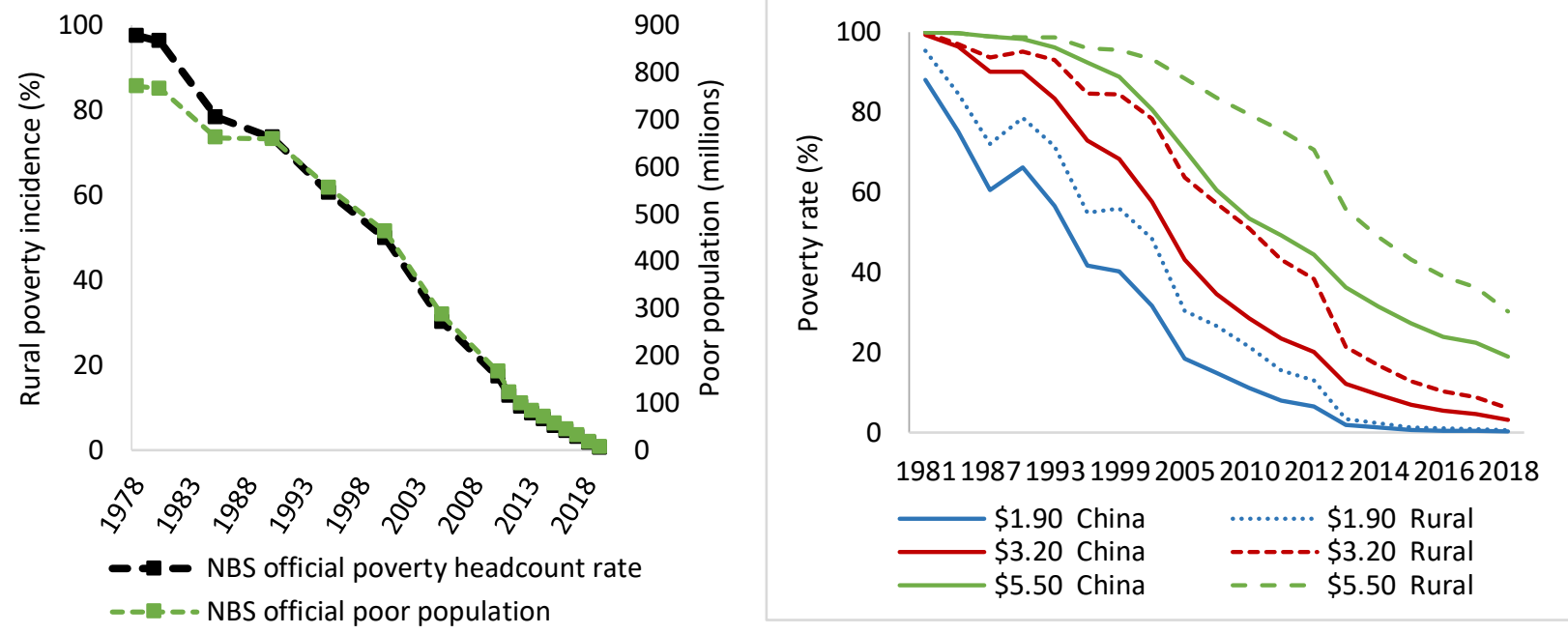

Sources: panel a uses official poverty headcount rate for rural areas is from China Statistical Yearbooks (NBS) using the 2010 standard -- equivalent to \$2.30 per person per day, 2011 Purchasing Power Parity. Panel b is based on PovcalNet 1981-2016, and 2017-18 preliminary estimates by the authors, based on NBS grouped data. $\$ 1.90$ /day (international poverty line), the $\$ 3.20$ /day line (typical of lower-middle income countries), and \$5.50/day line (typical of upper-middle income countries).

China's eradication of extreme poverty is of global importance. Between 1981 and 2017, using the international poverty line (\$1.90 per person per day, $2011 \mathrm{PPP})$, on average, there were almost 34 million fewer poor people in the world each year, with 24 million on them coming from China. China alone accounts for almost threequarters of the total reduction in global extreme poverty in that period (Figure2). The pace of poverty reduction in China has been consistently faster than in the rest of the world, considered as a whole.

\footnotetext{
${ }^{2}$ For comparability over time, poverty is measured using the 2010 Poverty standard, as reported by China's National Bureau of Statistics (NBS) Statistical Yearbook. It should be noted, however, that two other standards have been used in the past --the 1978 standard and the 2008 standard-- because they were more relevant at the time. Using those lower lines, poverty followed a similar pattern of continued decline, although they indicate a more noticeable slowdown in poverty reduction toward the end of the 1990s and into the mid-2000s.
} 
Figure 2: China accounts for almost three quarters of global extreme poverty reduction since 1981

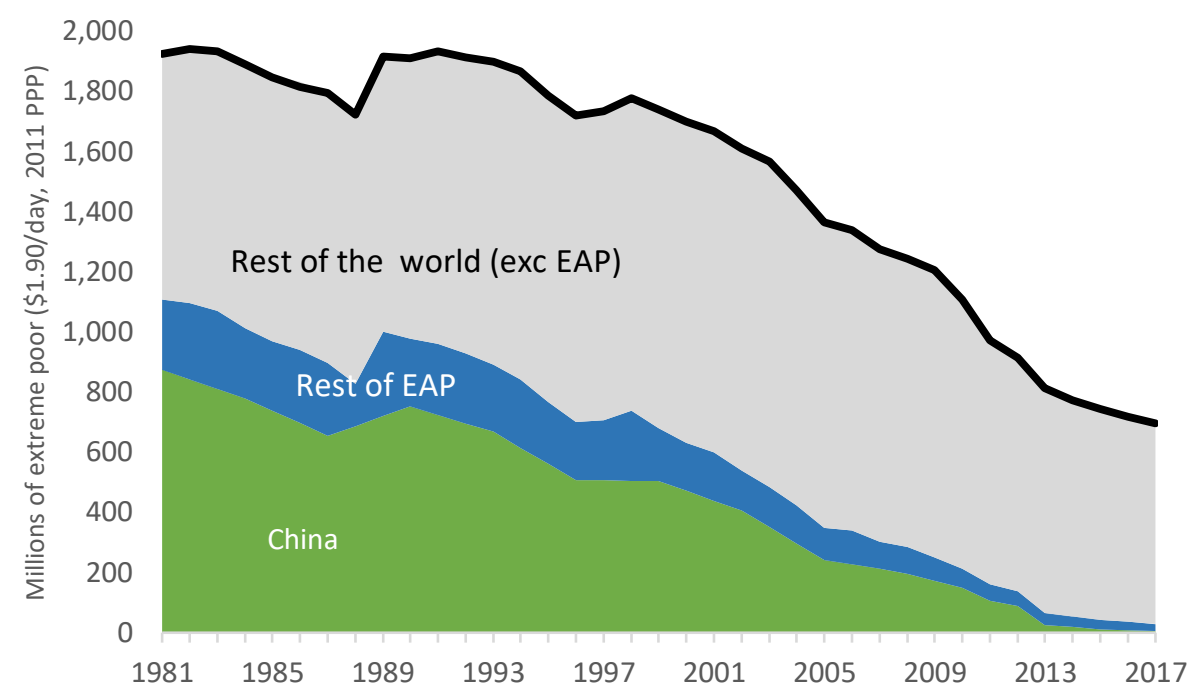

Sources: based on PovcalNet (World Bank 2018). China's estimates for 2017 are preliminary, produced by authors.

\section{Literature of poverty reduction in China and the contribution of this paper}

Naturally, China's poverty reduction experience attracted much attention globally and motivated a large literature. Taking only often-cited papers, books and reports on poverty evolution in China, we count more than 200 entries. These studies cover various aspects and stages of China's fight against poverty. This paper relies particularly on long-term perspective of poverty reduction in China covered, for instance, by Chen and Ravallion (2008, 2020), Luo et al (2020), Ravallion and Chen (2007), Shi et al. (2013, 2020), and Wang (2013).

The paper does not attempt to fully summarize this vast body of knowledge. Instead, we focus on the specific question of how the economic growth translated into improvement of living standards and poverty reduction. Our core question is which channels mattered the most for rural poverty reduction at various stages of economic transformation. To the extent possible, we look at the entire period of 40 years of reforms and opening up and use comparable data that allow us to tell the dynamic story.

To better understand the distributional forces behind poverty reduction in China we rely initially on decompositions of poverty changes by Ravallion and Datt (1992) and Ravallion and Huppi (1991) that allow us to describe roles of growth and inequality and relative importance of rural and urban poverty and population shift from rural and urban areas that occurred during this period (Section 2). These are done using grouped household survey data from the National Bureau of Statistics (NBS) spanning this period. To our knowledge, this is the first time these decompositions are applied to the entire 40-years period of poverty reduction in China using consistent poverty line. We also calculate growth elasticities of poverty and compare those across a set of comparator countries to understand the specifics of poverty reduction process in China and its distinct phases.

The main section of the paper aims to locate the most influential contributors to rural households' income growth in each of the periods (Section 3) and thus to poverty reduction. We do this by decomposing poverty changes across income components, following the approach developed by Barros et al. (2006) and expanded by Azevedo et al. (2013). Using data from the China Household Income Project (CHIP) from 1988 to 2018 (rural samples only), we simulate the distribution of welfare by changing each income component one at a time, 
and calculate their contribution to the observed changes in poverty and use Shapley-Shorrocks ${ }^{3}$ approach to aggregate across multitude of possible pathways. Such a decomposition is useful mainly as an accounting exercise --rather than to demonstrate the causal impact of each source--, to illuminate the relative importance of each sector, as well as the role of public and private transfers and property incomes. To the best of our knowledge, this is the first time that such an approach is applied to data from China spanning such a long period of time.

An important caveat of our analysis is that (unlike many other papers on China's poverty reduction, see Liu et al. 2020 for the most recent overview), we do not look at the effects of specific policies that were deployed by the government. To be sure, government policies, and specifically poverty reduction programs, played an essential role in improving the lives of the poor in rural areas. Economic reforms carried out throughout the decades were complemented by strategies, policies and programs directly targeted at poverty alleviation.

Following Liu et al. (2020), poverty alleviation strategies in China can be categorized in four stages according to the differences in focus of anti-poverty measures: relief-type poverty alleviation (1978- 1985); developmentoriented poverty alleviation (1986-2006); development-oriented poverty alleviation combined with social security system reforms (2007-2012); and targeted poverty alleviation (since 2013). The list of localities (counties) to be subject to special policy intervention changed over time, and the role of area-based programs changed as well. China incrementally refined the targeting of those poverty alleviation policies: moving from nationwide approaches to broad regionally targeted interventions, followed by more narrowly focused programs for poor counties and villages, and finally to poor households as the target of policy interventions. At the same time, it rapidly expanded social protection programs that directly targeted poor and vulnerable households, aiming to cover all those in need.

Several papers have studied the role of these policies. For instance, Park et al. (2002) find that the large-scale poverty alleviation program in 1986-92 had a modest positive effect on rural income growth in targeted poor counties and positive spillover to neighboring counties with higher incomes, despite leakages in targeting. Meng (2013), using regression discontinuity design, finds that the 8-7 National Plan for Poverty Reduction (19942000) resulted in an approximately 38 percent increase in rural income for counties that were treated between 1994 and 2000. Finally, Freije and Zhao (forthcoming) document the doubling of resources to anti-poverty development programs (and social insurance) since 2011. With data up to 2017, the authors find that these programs had a statistically significant but relatively small impact on poverty reduction.

For most of the analysis in this paper, we focus on rural poverty as measured using China's current poverty line (the so-called 2010 poverty standard). In China, poverty is measured by the official statistics only for rural households. The 2010 standard is equivalent to US\$2.30 per person per day in 2011 purchasing power parity (PPP) terms. In 1980, the share of people with incomes below the 2010 standard was 96.2 percent. At the time, the official poverty line was set at 206 yuan per year in 1985 prices, equivalent to $\$ 0.98$ in 2011 PPP terms. In 2008 , a new (higher) standard was set, at 865 yuan per year in 2000 prices equivalent to $\$ 1.30$ per person per day in 2011 US PPP. See annex 1 for a detailed description of the official poverty standards.

We argue that, although the current standard may be low by China's level of development today, it is nonetheless useful to describe the long-term evolution of poverty, for a country that was among the poorest economies in the early 1980s. ${ }^{4}$ Nevertheless, throughout the paper we present the evolution of key variables

\footnotetext{
${ }^{3}$ See Shapley (1953) and Shorrocks (1999).

${ }^{4}$ Chen and Ravallion (2020) compute poverty headcount rates, poverty gap, and severity of poverty for China, using varying thresholds,
} 
(household size, share of workers by sectors, and earnings) across quintiles of the (income) distribution in rural areas, and thus provide the elements to assess how the different parts of the distribution improved throughout the decades.

\section{China's development and poverty over the past 40 years}

This section uses publicly available official data on key poverty indicators to set the stage for a more detailed analysis in section 3. One such source is the poverty data cited as coming from the World Bank's "PovcalNet" database. The Government of China, through its National Bureau of Statistics, provides to the World Bank data on average household expenditure per capita for urban and rural areas across ventiles of the expenditure distribution, and their respective population shares (except for 1981 and 1987 for which per capita disposable income was provided). This data is used by the World Bank to compute poverty rates using international poverty lines to feed into the global poverty monitoring and is made available to the public to calculate poverty rates using alternative lines. ${ }^{5}$

\subsection{The growth, poverty and inequality triangle for China}

Poverty reduction in the past four decades was driven by fast growth. Per capita household incomes increased on average 8 percent per year between 1978 and 2018 (Figure ). ${ }^{6}$ At the beginning of the reforms, the economy grew fast - at more than 10 percent per year - with rural households' income rising faster than in urban areas, as agricultural productivity rose fast following land reform, liberalization of output markets and prices, and massive investments, among others. At the end of the 1980s amid the first wave of macroeconomic imbalances, growth decelerated. As the country embraced special economic zones in the urban coastal region, economic growth concentrated in these areas and urban incomes grew significantly faster than rural ones.

The second slowdown happened in the late 1990s, with the emergence of the Asian economic crisis as well as internal structural problems (Freije et al. 2019). The economy then regained its momentum, again reaching annual growth rates in per capital household incomes of about 10 percent. With the efforts in the 2000s to support growth in the lagging areas in the central and western regions, rural households' incomes, particularly in the western and central regions, grew faster and eventually surpassed the growth rates experienced in urban areas. Since 2015, overall growth in per capita household income has slowed across regions and areas of the country.

calibrated by the official lines relevant in each year. As expected, the decline in poverty is much less steep -from 24 percent in 1985 , to 20 percent in 2000, and to 16 percent in 2013. Implicit in this calculation is the idea that poverty lines depend on average income levels, rendering them partly relative ("weakly relative" in Chen and Ravallion terminology). Relative poverty lines are becoming increasingly important in China's debate. Yet, in this paper, we rely on the current official measure.

${ }^{5}$ See PovcalNet website http://iresearch.worldbank.org/PovcalNet and Ferreira et al. (2016) for a methodological description of the treatment of the data for China.

${ }^{6}$ This compound annual growth rate is based on 2019 NBS Yearbook Form 1-2 and Form 5-2. 
Figure 3. Per capita disposable income, rural vs. urban and by region, China (in 2018 yuan)

a. Household per capita income, rural vs urban

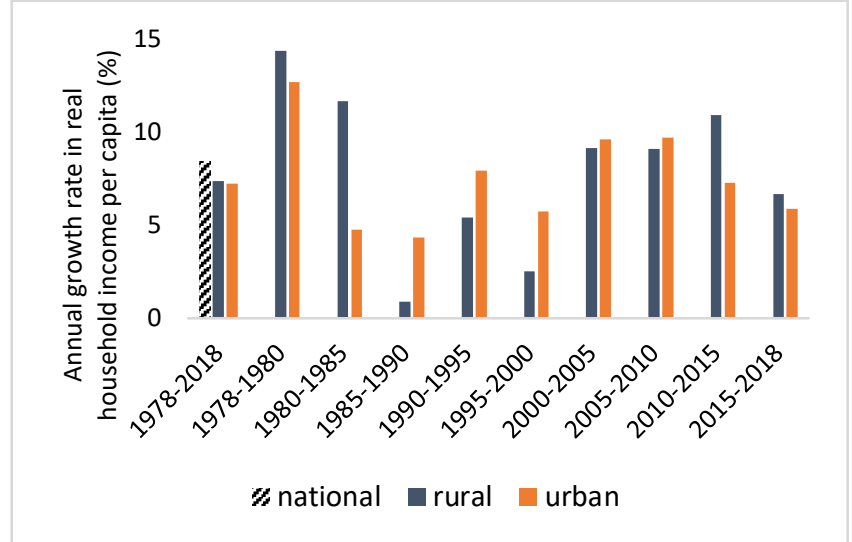

b. Household per capita income, by region

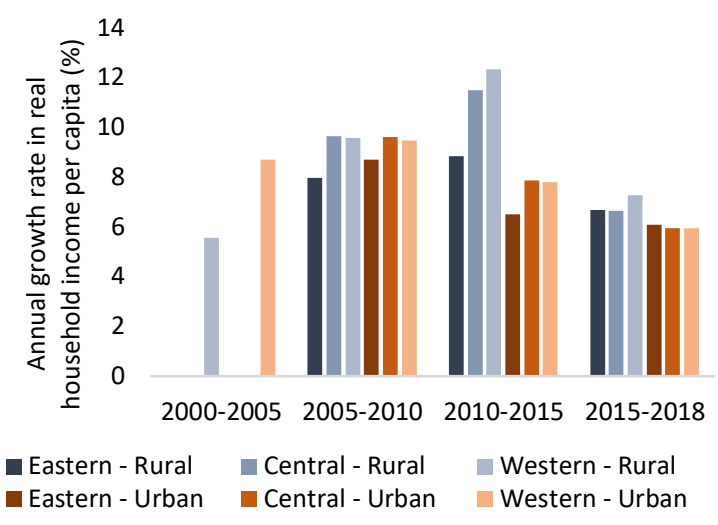

Source: authors' calculations based on NBS China Statistical Yearbooks per capita disposable incomes and consumer price indexes in urban and rural areas. Note: National consumer price index is used to deflate 1978 and 1980 rural incomes. All incomes are in 2018 Chinese yuan.

Growth was relatively fast across most of the distribution, although with sizeable differences over the decades. On average, annual per capita consumption growth was above 4 percent per year across percentiles of the distribution throughout the four decades (figure 4). During the 1980s, disposable income grew between 6 and 8 percent per year across most households in the distribution. By contrast, in the 1990s and the 2000s, consumption growth was significantly faster for richer households than for those in the bottom half of the distribution. Since 2010, the reverse is true; poorer households have experienced higher consumption growth, and significantly higher than those at the top 20 percent.

As a result, overall inequality increased steadily until 2010 and since then it has leveled off. The income-based Gini index rose from 30.0 in the mid-1980s to 49.1 in 2008 (Figure 4). This level is typically found in highly unequal Latin American economies or in Sub-Saharan Africa. As China moved to a market economy, however, it was expected that interpersonal disparities would increase. The fast development in coastal urban areas brought about spatial disparities with the lagging regions and rural areas.

The end of the 2000s represents a turning point, as the Gini index began to fall, declining to 46.2 by 2015 . This change in the trend is referred to in the literature as the "great Chinese inequality turnaround" (Kanbur et al. 2020). Reasons presented for the turnaround include the shift in public policies toward the development of the western and northern regions (initiated in the early 2000s), the end of agricultural taxation, the rise of social protection investments (creation of minimum support program and rural collective medical insurance schemes), and the increase in the minimum wage and its enforcement (Kanbur et al. 2020). Ravallion and Chen (2021) argue, instead, that because the moderation of inequality was driven by specific policies, the peak inequality may still lie ahead unless mitigated by policy. Indeed, in the last five years, despite further progress in extreme poverty reduction, improvements in income inequality stalled: the Gini coefficient was still 46.5 in 2019. 
Figure 4. Growth Incidence Curves and Gini Index, 1981-2018.

\section{a. Growth incidence curves}

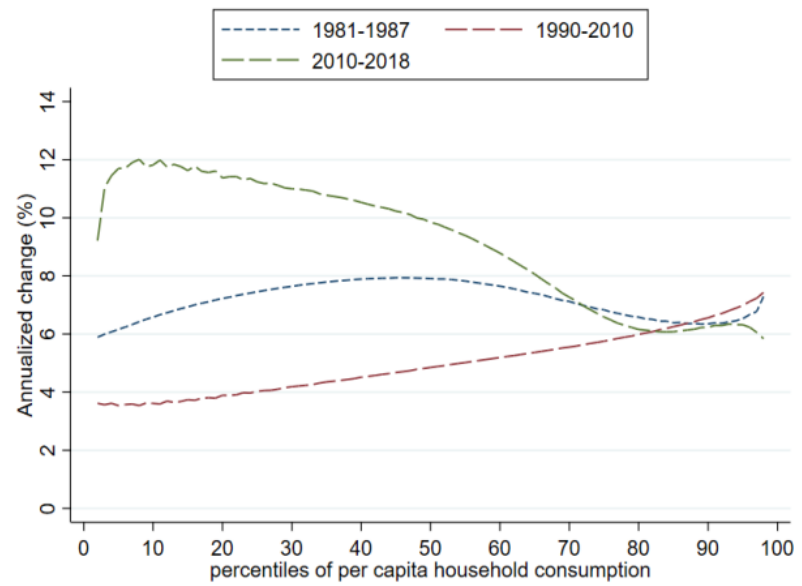

Source: Authors, based on PovcalNet. Note: data for 1981-1987 refers to real per capita income growth rates, whereas growth rates for 1990-2018 refers to real per capita consumption. b. Gini index

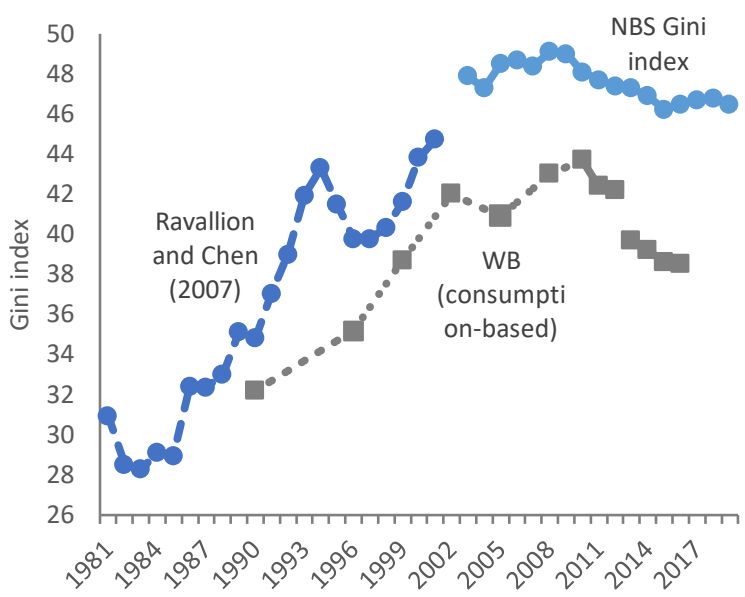

Sources: Income-based Gini index 1981-2001: Ravallion and Chen (2007) based on data provided by NBS. 2003-19 NBS Household Surveys Yearbook. Consumption-based Gini index: WB based on NBS tabulations.

Economic growth resulted in large declines in poverty levels. Applying the concept proposed in Bourguignon (2003) and Datt and Ravallion (1992), we calculate the unconditional growth elasticity of national headcount poverty reduction. The value (in logs) for China as a whole is -2 , meaning that for each percentage point growth in the average per capita consumption, poverty headcount rates reduced on average by 2 percent (Table 1). In terms of the elasticity with respects to the overall economic growth (per capita gross domestic product, [GDP]), the elasticity is smaller, at -1.45 , meaning that for each percentage point growth in per capita GDP, on average, poverty declined 1.45 percent. The difference in the elasticities is related to the high and increasing propensity to save in the country (as documented in Merotto and Jiang, 2021).

Yet, the rise in inequality reduced the impact of economic growth on poverty reduction. Once we control for inequality, the growth elasticity of poverty in absolute magnitude is much higher, closer to -3 in the case of mean income and to -2.7 in the case of per capita GDP. Elasticities in rural areas were generally smaller in absolute terms for rural areas compared to national level estimates, but the differences between unconditional elasticity and the estimate controlling for inequality are closer than national level estimates, suggesting that increases in inequality among rural populations were not as strong, and that growth impact on poverty was not attenuated as much as it was nationwide.

Table 1. Growth elasticities of poverty for China's rural areas and at the national level

\begin{tabular}{lccccc}
\hline & \multicolumn{2}{c}{ Mean income/consumption } & & \multicolumn{2}{c}{ Per capita GDP } \\
\cline { 2 - 3 } \cline { 5 - 6 } & Unconditional & $\begin{array}{c}\text { Controlling for } \\
\text { inequality }\end{array}$ & & Unconditional & $\begin{array}{c}\text { Controlling for } \\
\text { inequality }\end{array}$ \\
\hline Elasticity & & & & \\
National & $-1.988^{* * *}$ & $-3.014 * * *$ & & $-1.451^{* * *}$ & $-2.703^{* * * *}$ \\
& $(0.235)$ & $(0.215)$ & & $(0.215)$ & $(0.191)$ \\
Rural & $-2.113^{* * *}$ & $-2.312^{* * *}$ & & $-1.243^{* * *}$ & $-1.303^{* * *}$ \\
& $(0.255)$ & $(0.304)$ & & $(0.224)$ & $(0.285)$ \\
\hline
\end{tabular}

Source: Based on PovcalNet and World Development Indicators, using the international poverty line (\$1.90/day per person, 2011 purchasing power parity), household surveys income or consumption per capita, per capita GDP (constant 2010 US dollars), and Gini coefficients. Note: Elasticities of poverty with respect to per capita GDP are calculated using a regression of log of poverty headcount on log per capita GDP. *** significance at 95 percent confidence level. 
Figure 5. Decomposition of rural and national poverty in China into a growth and change in inequality components.

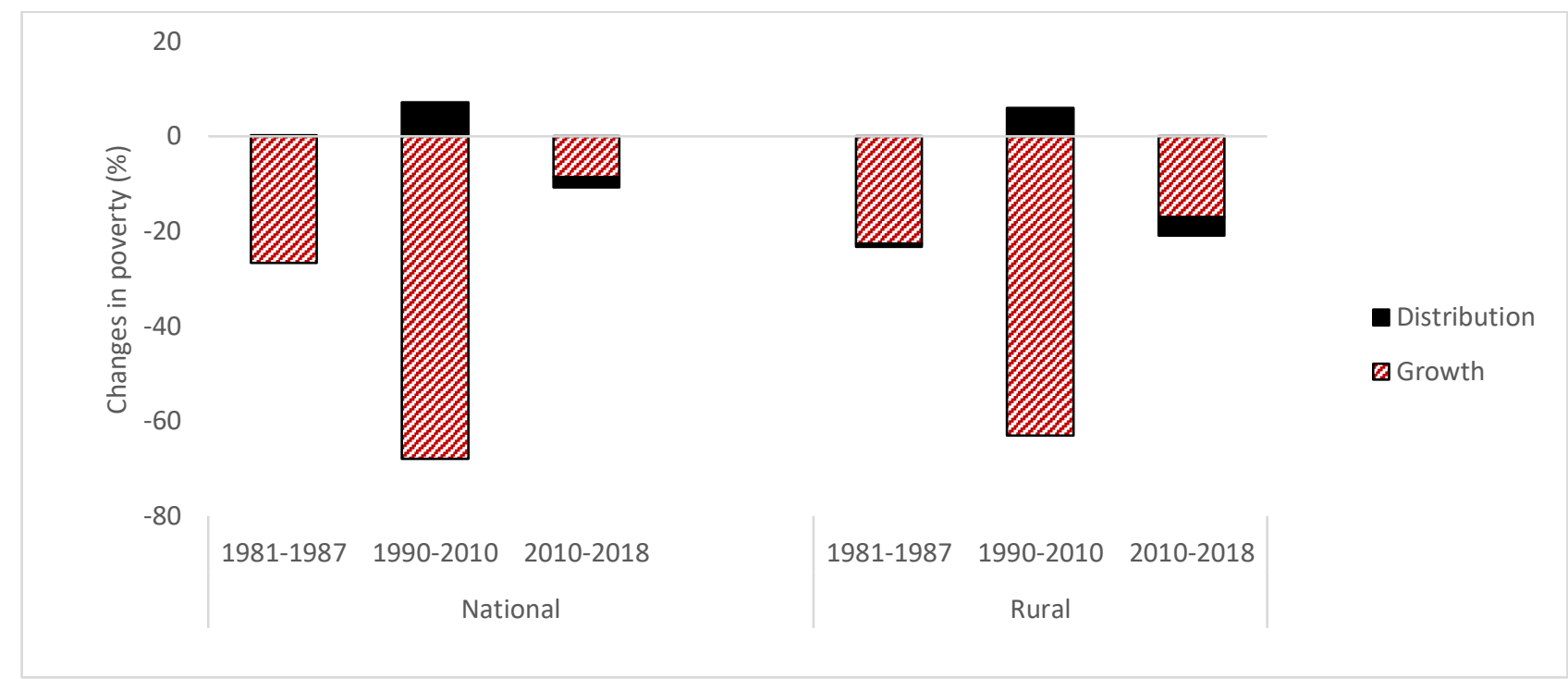

Source: Based on PovcalNet, using the international poverty line ( $\$ 1.90 /$ day per person, 2011 purchasing power parity). Note:

Methodology from Datt and Ravallion (1992).

The effect of growth and inequality can also be seen through the decomposition of changes in the incidence of poverty between changes in the overall mean and changes in the distribution, introduced in Ravallion and Datt (1992). With this method, we confirm that overall average growth drove poverty reduction throughout the period (Figure ). The component related to changes in the distribution slows down the pace of poverty reduction until the latest period (2010-18), though not enough to outweigh the effects of economic growth. Compared with long episodes of poverty reduction in other countries, the finding of growth effects dominating distributional effects is not unique in China. For example, the poverty rate in Pakistan could have reduced by 7.49 percent between 1992 and 2006 due to the growth effect alone, but inequality worsened, so that the net reduction in poverty was only 2.69 percent (Cheema and Sial, 2010) (Table 2). In India, Brazil and Mexico, growth and distributional effects complement in reducing poverty, but growth effects remain as the main contributor (Datt and Ravallion, 1992; Azevedo et al, 2014; Iniguez-Montiel, 2014). Even when the poverty level increases over time, such as in Cameroon between 1984 and 1996, the slowdown of growth is the defining factor (Baye 2006).

Table 2. Decomposition of poverty changes into growth and distribution for comparator countries

\begin{tabular}{lccccc}
\hline Reference & Country & Period & $\begin{array}{c}\text { Total change in } \\
\text { Poverty Rate }\end{array}$ & Growth & Distribution \\
\hline Cheema and Sial 2010 & Pakistan & $1992-2006$ & -2.69 & -7.49 & 4.80 \\
Datt and Ravallion 1992 & India & $1977-1988$ & -15.79 & -9.74 & -6.05 \\
Iniguez-Montiel 2014 & Mexico & $1992-2008$ & -5.93 & -3.37 & -2.56 \\
Azevedo et al 2013 & Brazil & $2001-2009$ & -15.5 & -8.37 & -7.13 \\
Baye 2006 & Cameroon & $1984-1996$ & 0.24 & 0.26 & -0.02 \\
\hline
\end{tabular}

Sources: see references.

How does China's long-term growth elasticity of poverty compare with other countries? Because elasticity is affected by the initial level of poverty, when making international comparisons it is useful to look at the poverty semi-elasticity of growth. This represents the percentage point reduction in poverty (rather than percent 
reduction) with every percentage point of economic growth. ${ }^{7}$ Compared with other countries with data available for at least 20 years, China's ability to convert growth into poverty reduction is high though not the largest (Figure ). Pakistan, Indonesia, Vietnam, South Africa and Brazil show significantly higher levels of semielasticities. What makes China quite unique is its ability to grow fast, for a long period of time, as can be seen in Figure (panel b).

Figure 6. Growth semi-elasticity of poverty around the world

a. Semi-elasticities of poverty to per capita GDP across countries

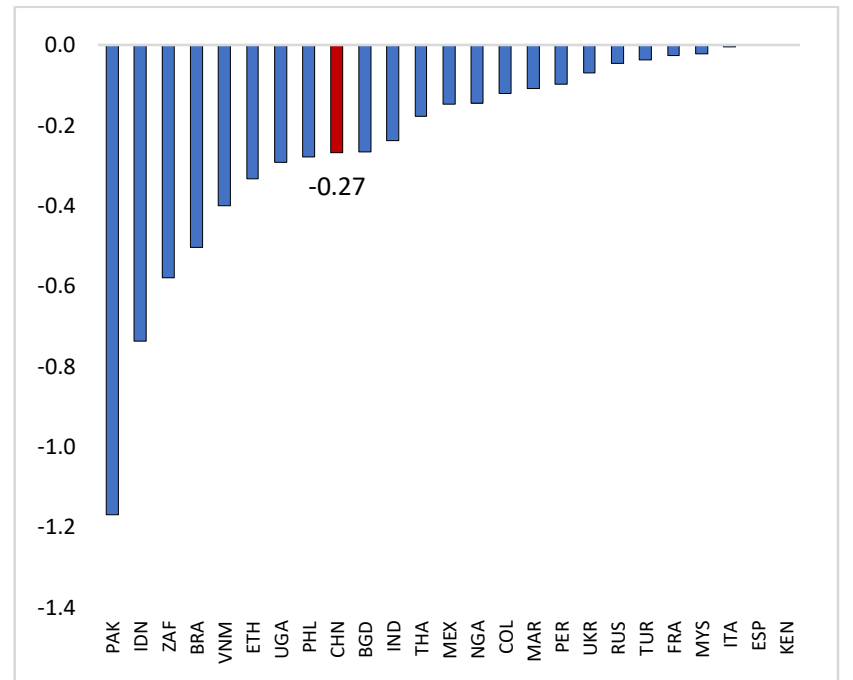

b. Semi-elasticity of poverty by average GDP per capita growth rate (annualized)

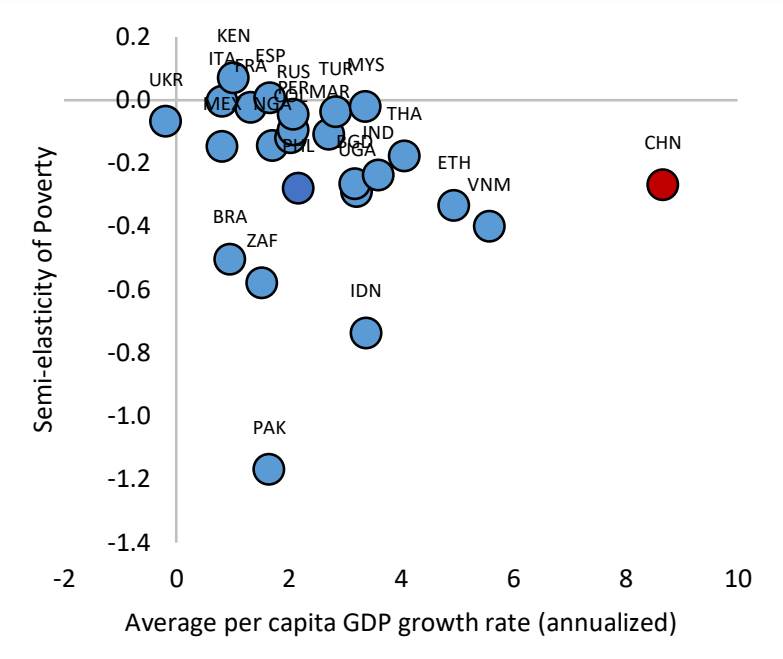

Source: Authors' estimate using PovcalNet and World Development Indicators, based on the international poverty line ( $\$ 1.90 /$ day per person, 2011 purchasing power parity) and per capita GDP (constant 2010 US dollars). Countries are chosen if data on poverty headcount rate and per capita GDP are (1) available in a timespan more than 20 years and less than 40 years, (2) have at least five data points within the timespan, and (3) have population over 30 million at the end of the period. Semi-elasticity of growth with respect to per capita GDP is calculated using a regression-based approach.

\subsection{Demographic transformation}

Over the past 40 years, China underwent enormous changes in its demographic structure. The policy efforts ensured the start of the demographic transition early on. Over the period 1949-79, average annual population growth was a little under 2 percent, similar to other developing countries. From 1965 to 1979, however, the birth rate almost halved --a faster decline than that recorded in any other country. Progress in universalizing education, especially for girls, and reduction of infant mortality were the main contributing factors. At the end of the 1970s, Deng Xiaoping, chief architect of China's reform and opening, emphasized that the rapid population growth in the previous decades had been unfavorable to economic and social development. In 1982,

\footnotetext{
7 The concept of semi-elasticity is used widely for international comparisons. Klasen and Misselhorn (2008, 4) note that "when the poverty incidence becomes small, large percentage changes in poverty incidence are easily achieved and it seems difficult to treat poverty reduction from an incidence of 2 to $1 \%$ in the same manner as poverty reduction from an incidence of 80 to $40 \%$.... it can be shown that in growing countries (and a constant real absolute poverty line), the growth elasticity of poverty reduction will keep going up, giving the misleading impression of growth not only being 'good for the poor', but becoming ever better for them over time.". Still, the conclusion does not change if we consider the elasticity rather than the semi-elasticity. Using the \$1.90/day line, China's GPD to poverty elasticity (conditional on inequality) is -2.95 , similar to Morocco (-3.08) and Mexico (-2.92). These elasticities fall somewhat in the middle of the full range of elasticities estimated, between the maximum levels found in France (-8.79), the Russian Federation (-6.82) and Pakistan (-5.48), and the minimum negative levels found in Nigeria (-0.31), Uganda (-0.58), India (-0.66) and Ethiopia (-0.70).
} 
family planning was incorporated into the Constitution, establishing its fundamental role in shaping demographic transformation in the reform period. ${ }^{8}$

Since then, the Chinese economy benefited from an economically favorable demographic structure, in which the working-age population rose and the dependency ratio declined, creating substantial demographic dividends that fueled the rapid economic growth. The share of the working-age population rose from 62 percent in 1982 to 73 percent in 2015, whereas the dependency ratio fell from 62 to 37 percent (Figure 7); the total fertility rate remained lower than 2 births per women over her lifetime in the same period.

Large gaps in the dependency ratio between urban and rural areas narrowed over the years. It took more than a decade for rural areas to reach the same level of dependency ratio that urban areas had in the late 1980s (Table 3). In 1988, households in rural areas had a significantly larger share of children than households in urban areas (26.6 percent compared to 20.0 percent), but this share declined rapidly, reaching 15 percent by 2007 . The same decline was happening in urban areas but aging there began earlier than in rural areas. In 2007, almost 10 percent of urban household members were over 65, compared to only 6 percent in rural households. By 2013, rural and urban households had relatively similar age structures. Even differences within income quintiles in rural areas narrowed over the years, as the share of children declined in rural households across the distribution. Yet the average share of elderly among poorer rural households grew more rapidly than among richer households. In 2013, the share of members over 65 years was 11.0 percent in the poorest quintile and 6.6 percent in the richest one.

Notably, there is a fundamental difference in the workforce participation of the elderly between urban and rural areas: In 2013, less than 10 percent of people over 65 living in urban areas were working, and fewer older than 70 were doing so. In contrast, almost half of rural elders between 65 and 69 were receiving either wage or business income, and about a third of those between 70 and 75 were doing so (Table 3). Therefore, although elderly members of rural households may rely to some (or a large) extent on earnings from other family members, they cannot be considered, in a traditional sense, fully dependent on nonlabor income. ${ }^{9}$

\footnotetext{
${ }^{8}$ Since the early 1970s China had one of the world's most active and effective fertility reduction programs. Contraceptives were made universally available and free. There was also a successful effort to raise the age of marriage. And, since 1979, there has been a policy in place to promote the one-child family. That policy provided incentives (such as financial allowances and priority in education, employment and housing for couples who pledge to have only one child), combined with financial penalties for those who have more than two children.

${ }^{9}$ Hence, in our decomposition analysis in Section 3 we rely on the dependency ratio taking into consideration all members above 14 year-olds as potential workers.
} 
Figure 7. Demographic transformation since early 1980s

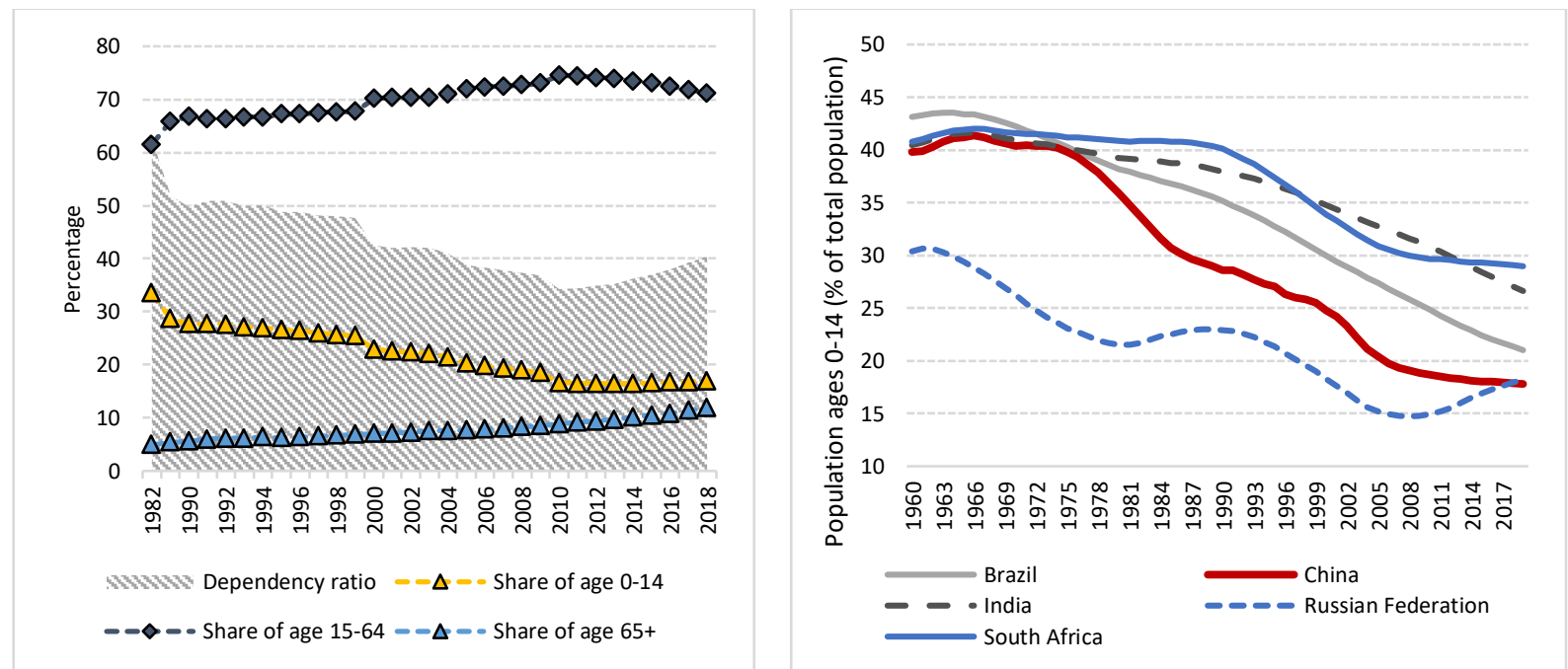

Source: left, NBS Yearbook 2018. Dependency ratio is defined as the share of children and elderly over the share in the working age. Right, World Development Indicators.

Table 3. Demographic transformation since early 1980s in rural and urban areas

\begin{tabular}{|c|c|c|c|c|c|}
\hline & 1988 & 1995 & 2002 & 2007 & 2013 \\
\hline & \multicolumn{5}{|c|}{ Dependency ratio } \\
\hline Urban & 0.41 & 0.36 & 0.31 & 0.32 & 0.38 \\
\hline Rural & 0.62 & 0.54 & 0.41 & 0.36 & 0.40 \\
\hline Poorest quintile & 0.72 & 0.62 & 0.52 & 0.43 & 0.50 \\
\hline Quintile 2 & 0.65 & 0.57 & 0.43 & 0.36 & 0.41 \\
\hline Quintile 3 & 0.55 & 0.50 & 0.35 & 0.29 & 0.33 \\
\hline Quintile 4 & 0.51 & 0.48 & 0.30 & 0.24 & 0.24 \\
\hline \multirow[t]{2}{*}{ Richest quintile } & 0.38 & 0.34 & 0.25 & 0.22 & 0.21 \\
\hline & \multicolumn{5}{|c|}{ Percentage of household members aged 0-14 (\%) } \\
\hline Urban & 20.4 & 16.8 & 13.2 & 11.8 & 14.4 \\
\hline \multirow[t]{2}{*}{ Rural } & 26.6 & 23.5 & 18.0 & 15.3 & 15.3 \\
\hline & \multicolumn{5}{|c|}{ Percentage of household members aged 65 above (\%) } \\
\hline Urban & 4.5 & 6.1 & 6.9 & 9.6 & 9.9 \\
\hline \multirow[t]{2}{*}{ Rural } & 4.5 & 4.7 & 5.1 & 6.1 & 9.2 \\
\hline & \multicolumn{5}{|c|}{$\begin{array}{l}\text { Percentage of household members aged } 65 \text { above and } \\
\text { working (\%) }\end{array}$} \\
\hline Urban & 0.1 & 0.2 & 0.1 & 0.3 & 0.7 \\
\hline Rural & 0.7 & 0.9 & 1.2 & 3.1 & 2.9 \\
\hline Rural poorest quintile & 0.7 & 1.0 & 1.3 & 4.0 & 3.4 \\
\hline
\end{tabular}

Source: Based on CHIP 1988-2013. Note: Quintiles of per capita disposable income across the national distribution 


\subsection{Role of urbanization and migration}

China's reforms started when the country was predominantly rural. Official estimates put the urban population share at 13 percent in 1979 -very similar to the proportion in 1953, and much lower than the proportions in other developing countries at this time (India, 22 percent; Indonesia, 20 percent; all low-income countries, 21 percent; all middle-income countries, 51 percent). This low urbanization reflects the policy of "industrialization without urbanization" pursued since 1957 when migration to urban areas was restricted.

Since that time, urbanization has been increasing steadily with income (Figure 8). Alongside institutional reforms and economic growth, the urbanization rate in China grew steadily from 19.4 percent in 1980 to 64 percent in 2020 (Source: NBS). China's pattern of urbanization and growth is similar to other countries in the world (Figure 8, panel a), particularly when compared with those that went through similar process of fast economic transformation, such as Vietnam or India (Figure 8, panel b). Such an urbanization process is still in action and has great potential, because the share of urban population in China is still lower than many other countries that have reached the upper middle-income status. For example, when Brazil, Mexico, and the Russian Federation were at a similar level of GDP per capita as China is today, their share of urban population was about 10 percentage points higher than that in China.

\section{Figure 8. Urbanization and development around the world}

a. Urban population share by GDP per capita, all countries.

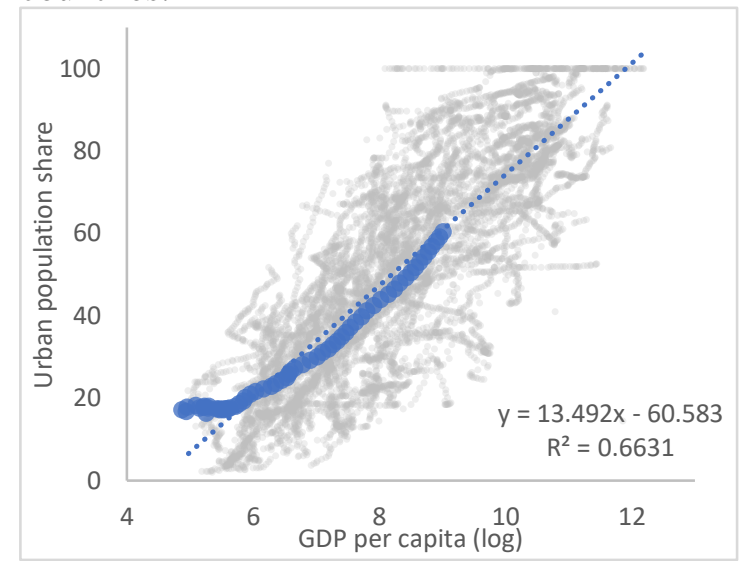

Source: World Development Indicators, World Bank.
b.Evolution of urban population share by GDP per capita, selected countries.

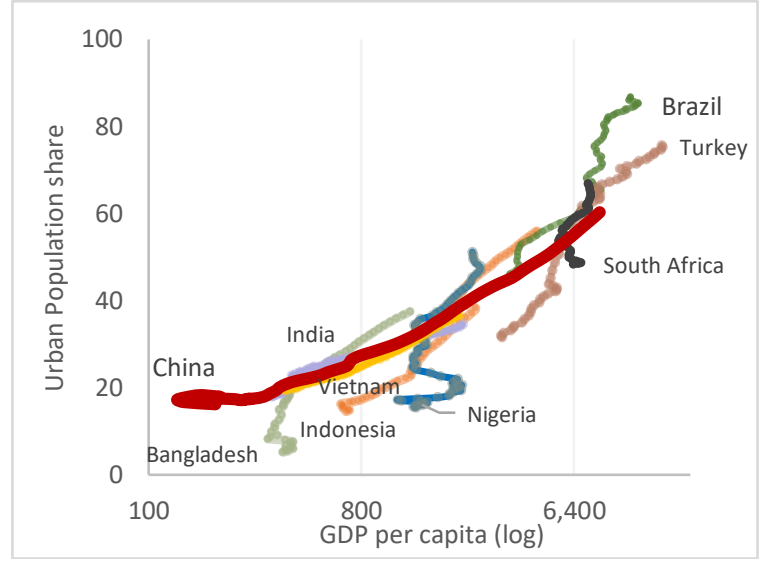

At the same time, China has one of the largest numbers of internal migrants in the world. Rural-to-urban migration became a significant phenomenon in the 1980s with the emergence of the market economy and shaped by the household registration (hukou) system. The registration system was established in 1958 to achieve a "meticulous planning and comprehensive control of where the population lived and worked" (Giles and Mu, forthcoming: p. 2). As demand for labor increased in urban areas and increases in agricultural productivity released workers from traditional agriculture in rural areas, the government adopted more flexible policies by introducing the legal status of "guest workers" to migrants. Rural-to-urban migration accelerated in the late 1990s as opportunities in urban areas across the country (not only coastal) expanded and restrictions on labor mobility were further reduced. The latest official statistics for 2018 indicate that over 288 million rural residents migrated to cities for work, with 172 million migrating outside their home townships to cities for work. ${ }^{10}$

\footnotetext{
${ }^{10}$ Statistics from Giles and Mu (forthcoming) based on "National Monitoring and Survey Report on Rural Migrant Workers 2018" released by the National Bureau of Statistics.
} 
The movement out of rural areas and into richer urban areas had a direct effect on poverty reduction. Although official poverty is measured only in rural areas, it is worth analyzing the direct role of urbanization in the process of poverty reduction, because a significant proportion of the rural population migrated to urban areas with evergrowing boundaries. If one considers poverty at the national level, using an equivalent poverty threshold for urban areas, once adjusted by differential cost of living, it is possible to decompose the total change in national poverty headcount into three components: reduction in rural poverty, reduction in urban poverty, and population shift from rural to urban areas (Ravallion and Huppi 1991). It should be stressed that this decomposition captures only the direct effect of people moving out of rural areas, and not the potentially more substantial role of migration through increased family transfers of migrants to their household of origin (often considered in the surveys as part of household labor income).

Population shifts from rural to urban areas became an important contributor to national poverty reduction only since the early 2000s (Figure 9). Early research covering the first two decades since the reform indicated that about 75 percent of national poverty reduction between 1980 and 2002 could be attributed to lowering headcount in rural areas, whereas between 20 and 24 percent is linked to shifting populations from rural to urban areas (Ravallion and Chen 2007). Updating this work and considering higher poverty lines (the international poverty line of $\$ 1.90$ per day per person in 2011 USD PPP), we find that poverty reduction within urban areas was also considerable in this first period. At this higher standard, accounting for cost-of-living differentials, the share of urban population below this threshold fell from 59 percent in 1981 to about 14 percent in 1996 and 5 percent in 2002. It is only since 2002 that we find population shifts starting to contribute more noticeably to the process of poverty reduction. Specifically, 16 percent of poverty reduction between 1996 and 2002 and 24 percent in the period between 2002 and 2018 can be attributed to population shift (Figure ). This reflects the gradual relaxation of the hukou system, which started in 1998 and accelerated since 2014, from fully restrictive to increasingly relaxed except for first-tier cities.

Figure 9. The role of rural-to-urban population shifts in poverty reduction, 1981-2018.

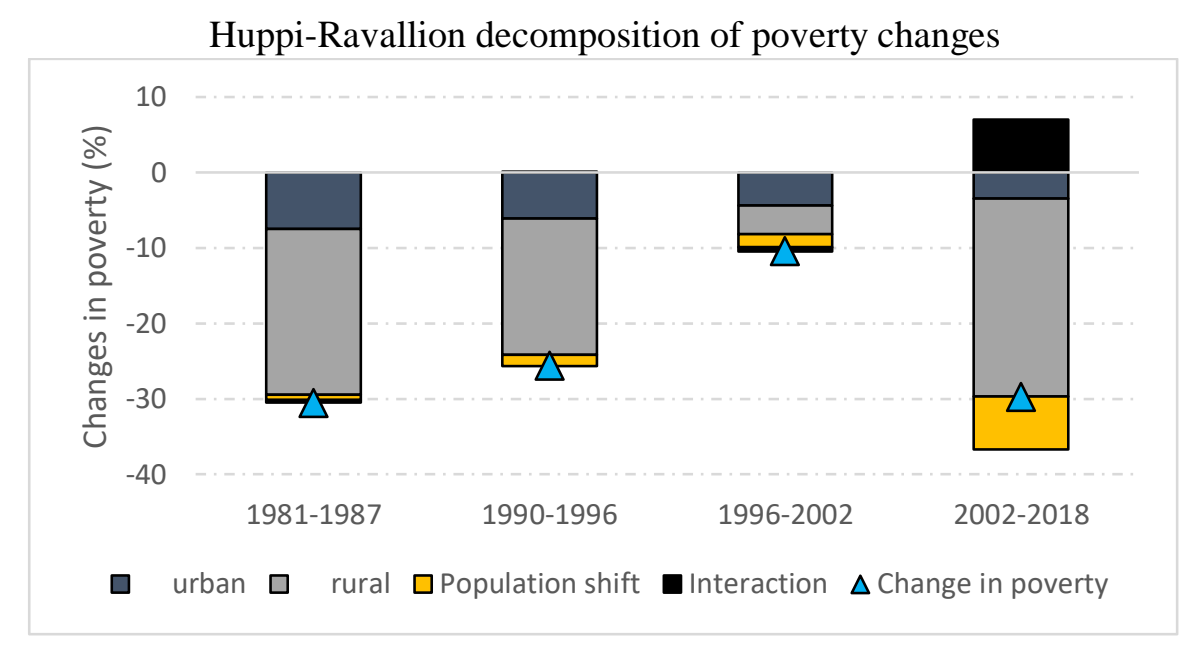

Source: Based on PovcalNet, using per capita disposable income for 1981-87, per capita household expenditure from 1990 onward, international poverty line $\$ 1.90$ per day standards, and adjusting for rural-urban cost-of-living differentials. Note: The interaction term captures the joint effect of shifts in the population and the differential in the speed of poverty reduction bewteen urban and rural areas (see Ravallion and Huppi 1991 for methodological description).

Migration from rural to urban areas even of temporary nature also has contributed to economic growth and poverty reduction directly by allowing workers to move to more productive employment. Part of their increased earnings is reflected in higher household income in rural areas, and thus in poverty reduction there. The HuppiRavallion decomposition, as a simple accounting exercise, is not able to capture such process. Giles and Mu 
(forthcoming) review the most reliable evidence on the benefits of rural-to-urban migration as a means for poverty alleviation in China. They show that there is convincing evidence that migration increased earnings and consumption in rural households with migrant members and reduced the probability of falling into and remaining in poverty. In this section, we present the additional role that increasing urbanization played in poverty reduction.

\section{Sectoral changes and poverty reduction}

As China's economy transformed, people's sources of incomes shifted, changing the drivers of poverty reduction. The country's fast growth was driven by both increasing productivity within sectors (starting with agriculture) and movement of workers from less-productive agriculture, to more productive, better-paid manufacturing and services. This section studies how these economy wide sectoral shifts manifested themselves on rural households' incomes, and thus driving rural poverty reduction. The analysis is done considering five distinct phases, mapped to survey data collection waves, and reflective of changing directions of economic development (Table 4).

The reform process underlying these phases was in fact continuous (Fang et al. 2018, Freije et al. 2019). Some reforms took decades to be fully implemented, and progress happened on many fronts simultaneously. Therefore, any subdivisions of this ascent are somewhat arbitrary, based on the most noticeable results achieved and, hence, the changing drivers of poverty reduction. Over these five phases, economic growth remained strong and rural poverty declined consistently. Between 1978 and 2019, per capita GDP grew at an annualized rate of 8.4 percent, while the poverty rate fell, on average, 2.4 percentage point per year, with approximately 19 million fewer poor people every year (Table ). As shown in Freije and Zhao (forthcoming), the largest yearly absolute decline was in the 2000s, when growth reached almost 10 percent and almost 30 million people were lifted out of poverty every year. Poverty reduction continued strong after 2010, even as economic growth slowed, thus reflecting a higher growth elasticity of poverty. Since 2013, as the share of rural poor fell below 10 percent, the average reduction in poverty has declined at a time when per capita GDP grow has also slowed.

Table 4. Five phases of poverty reduction in China, since 1978

\begin{tabular}{|c|c|c|c|c|c|c|c|c|c|}
\hline \multirow[b]{3}{*}{ year } & \multicolumn{6}{|c|}{ Rural poverty } & \multirow{3}{*}{$\begin{array}{l}\text { Per capita } \\
\text { GDP growth } \\
\text { (percent, } \\
\text { annualized) }\end{array}$} & \multirow{3}{*}{$\begin{array}{c}\text { Growth semi- } \\
\text { elasticity of } \\
\text { poverty }\end{array}$} & \multirow{3}{*}{$\begin{array}{c}\text { Growth } \\
\text { elasticity of } \\
\text { poverty }\end{array}$} \\
\hline & \multirow[b]{2}{*}{$\begin{array}{r}\text { headcount } \\
\text { (million) }\end{array}$} & \multirow[b]{2}{*}{$\begin{array}{c}\text { rate } \\
\text { (percenta } \\
\text { ge) } \\
\end{array}$} & \multicolumn{4}{|c|}{ Change } & & & \\
\hline & & & period & $\begin{array}{l}\text { absolut } \\
\text { (million } \\
\text { per year) }\end{array}$ & $\begin{array}{l}\text { e decline } \\
\text { (percentage } \\
\text { point per }\end{array}$ & $\begin{array}{c}\text { relative decline } \\
\text { (percent, } \\
\text { annualized) }\end{array}$ & & & \\
\hline 1978 & 770 & 97.5 & & & & & & & \\
\hline 1990 & 658 & 73.5 & $1978-1990$ & -9.3 & -2.0 & -2.3 & 7.5 & -0.27 & -0.31 \\
\hline 2000 & 462 & 49.8 & $1990-2000$ & -19.6 & -2.4 & -3.8 & 9.3 & -0.26 & -0.41 \\
\hline 2010 & 166 & 17.2 & $2000-2010$ & -29.7 & -3.3 & -10.1 & 9.9 & -0.33 & -1.02 \\
\hline 2013 & 82 & 8.5 & $2010-2013$ & -27.7 & -2.9 & -20.9 & 7.9 & -0.37 & -2.66 \\
\hline \multirow[t]{2}{*}{2019} & 6 & 0.6 & $2013-2019$ & -12.8 & -1.3 & -35.7 & 6.3 & -0.21 & -5.64 \\
\hline & & & $1978-2019$ & -18.7 & -2.4 & -11.7 & 8.4 & -0.28 & -1.40 \\
\hline
\end{tabular}

Source: Poverty headcount and rate from NBS Yearbook, 2010 Standard. GDP per capita growth based on per capita GDP (constant 2010 US dollars) from the World Development Indicators. Growth elasticity of poverty is the percentage change in poverty headcount rates associated with a one percentage point change in per capita GDP. Semi elasticity is defined as the percentage point change in poverty headcount rate for a one percent change in per capita GDP. 


\subsection{Methodology and data used in this section}

To explore drivers of poverty reduction over three decades from 1988 to 2018, we decompose poverty changes according to households' income sources. We apply a methodology developed by Barros et al. (2006) and expanded by Azevedo et al. (2013).

This methodology simulates the distribution of welfare by changing each of income components one at a time, to calculate their contribution to the observed changes in poverty, and then using Shapley-Shorrocks approach to aggregate across multitude of possible pathways, where poverty headcount for each year is defined as in equation (1), where $\mathrm{N}$ is the population, $\mathrm{k}$ denotes the individual index, $n_{k}$ is the number of members in individual k's household, $n_{k}^{A}$ is the number of adult members in individual k's household, $y_{k}^{j}$ is individual k's labor income earned from sector $\mathrm{j}, y_{k}^{h}$ is individual k's portion of incomes received by k's household such as transfers and property incomes (we assume equal shares for each household member), $\mathrm{z}$ is the poverty line in terms of per capita household income.

$$
\begin{gathered}
P=\frac{1}{N} \sum_{k=1}^{N} I\left\{\frac{n_{k}^{A}}{n_{k}}\left[\frac{1}{n_{k}^{A}}\left(\sum y_{k}^{j}+\sum y_{k}^{h}\right)\right]<z\right\}, \\
\mathrm{j} \in\{\text { agriculture, industry, service }\}, \mathrm{h} \in\{\text { transfer, property }\}
\end{gathered}
$$

The aim is to locate the most influential contributor to households' income growth in each of the periods. Such a decomposition is useful mainly as an accounting exercise (that is, rather than to demonstrate causality), to illuminate the relative importance of each sector, as well as the role of public and private transfers and property incomes. It is the first time such an approach is used for data form China. It was applied for Latin America (Azevedo et al. 2013), Turkey (Azevedo and Atamanov 2014), Brazil, and a number of other countries.

We do not reproduce the full set of formulae of decomposition here (which is available in Azevedo et al. 2013), and rely on Stata program described in Azevedo, Nguyen, and Sanfelice (2012), which allow the application to survey data with multiple rounds, using round-by-round comparisons.

The analysis focuses on the evolution of total income, which includes both labor and nonlabor components. Household labor incomes are further divided by sector of employment into agriculture, industry, and services. Nonlabor income includes transfers and property income. In addition, the change in the number of adults in households captures the demographic composition factor. The growth in total income equals the weighted sum of growth in each of the six components. Figure 10 shows schematically how the decomposition is performed. 
Figure 10. Decomposition Framework

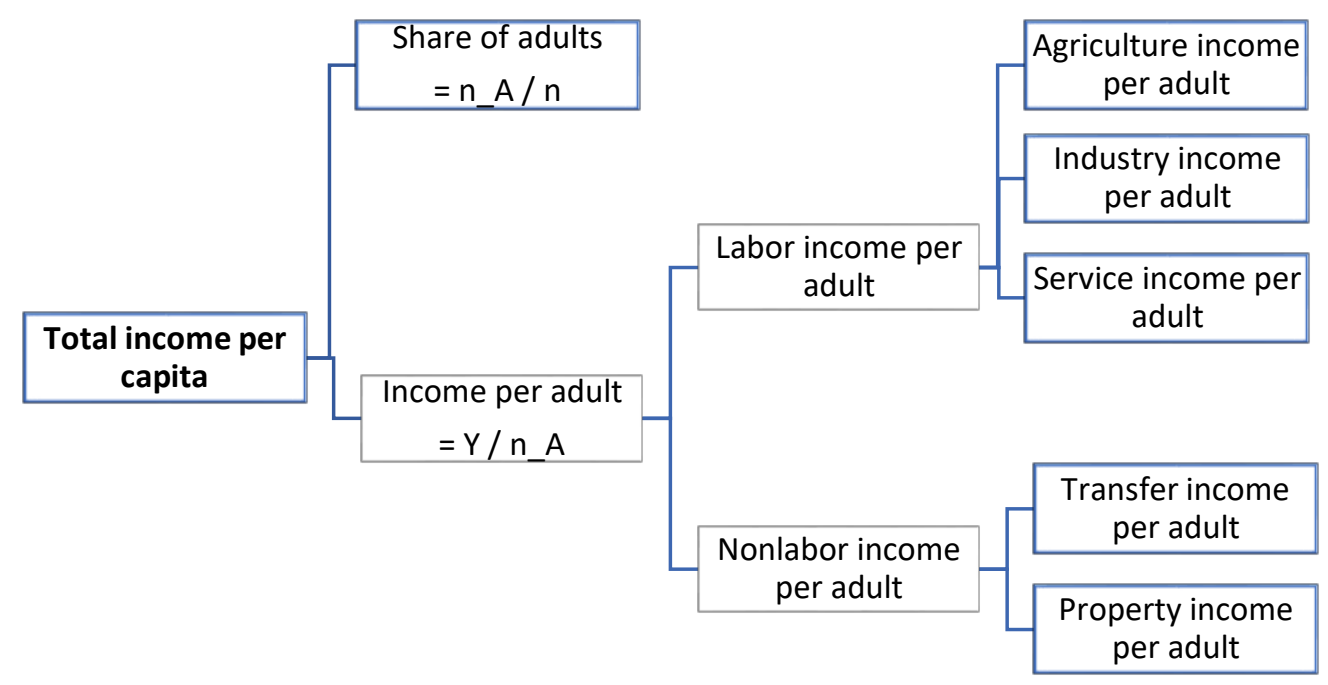

Source: adaptation from Azevedo et al. (2013).

The analysis in this sector is, for the most part, based on data from the Chinese Household Income Project (CHIP). The project is part of the activities carried out by the China Institute for Income Distribution of Beijing Normal University. The CHIP survey is implemented by a mix of research institutions and academics in coordination with NBS. There are 5 rounds of CHIP already released publicly $(1988,1995,2002,2007,2013)$ covering rural and urban areas. The survey is representative at the urban/rural level and regional level (4 regions). ${ }^{11}$ Analysis using 2018 CHIP survey was performed directly by CHIP team, in collaboration with the Center on International Knowledge for Development (CIKD), and in close coordination with the authors of this paper. In addition to being publicly available until 2013, the CHIP dataset is richer than the official household survey on several issues of interest, in particular, covering labor market participation. Finally, compared to other research initiated household surveys, CHIP survey has the advantage of covering three decades of poverty reduction.

CHIP surveys are a good alternative to official data. They are an approximately 20 percent sub-sample of the official household survey (with a sample of approximately 20,000 households). For 2007 onwards, NBS provides income and expenditure aggregates as reported in the official household survey. ${ }^{12}$ Households from the official household survey are revisited about 6 months later to implement the CHIP questionnaire which captures rich information on hukou registration, education, social insurance, employment and job characteristics, retirement conditions, education and occupation of parents of head of households, as well as subjective well-being. The richness of this survey means that, even if access to official survey data were available, it is useful to complement that analysis using CHIP. Crucially, the official household survey does not contain sufficient information to decompose total labor income by sector of employment, needed to perform the sectoral decomposition proposed in our paper.

Since 2002, CHIP also includes a sample of rural-urban migrant households, which were excluded from the official data until 2013. As discussed in Giles and Mu (2021), since the late 1990s, an increasing share of workers with rural hukou spent part or all of their time working in urban areas. As these individuals are unlikely

\footnotetext{
${ }^{11}$ Gustaffson et al. (2008) and Li et al. (2013).

${ }^{12}$ Strictly speaking, NBS income and consumption variables are available for rural households in 2007 and 2013 , but only in 2013 for urban households.
} 
to be captured in either urban or rural surveys, the CHIP migrant sample is able to fill a gap in coverage. The sample aims to get at the more established, permanent migrants, that is, people that have rural hukou but have lived in urban areas for more than six months (which is institutionally considered an important cut-off giving migrants greater rights and access to services). The analysis in the present section is restricted to the rural sample, since the objective is to understand the drivers of poverty reduction in rural areas. Permanent rural migrants living in urban areas would contribute to poverty reduction in rural areas in as much as they remit part of their income to their rural families. These transfers should be captured in the "transfer component". As we mention below, however, more temporary migrants or those with strong economic attachments to rural households would be included as members of households in the rural samples. Therefore, disentangling the effect of remittances, more broadly understood to include any transfer from rural migrant workers to rural households, will be difficult.

In this paper, we calculate poverty based on per capita disposable income. There are several reasons for this choice. First, the welfare aggregate used in official statistics changed over the period analyzed while we want to maintain the same aggregate throughout. From 1985 to 1997 the welfare aggregate used for official poverty measurement was per capita disposable income. It then transitioned to a combination of income and expenditure from 1998 to 2010 (poor was defined as those whose income was below the poverty line and expenditure below 1.5 times the poverty line, or vice versa). Since 2011, poverty is measured using exclusively per capita household expenditure. ${ }^{13}$ Second, in the earlier rounds of the CHIP surveys, official NBS expenditure and income data is not available, and thus we need to rely on CHIP measures of welfare. As information is obtained through recall (rather than by diary as in the official survey), and with absence of essential expenditure categories such as clothing in early waves, income is perceived to be more accurate. Thirdly, since the purpose of the present study is to link macro sectoral movements with changes in household welfare, changes of incomes from different sources provide a direct approach for such analysis. Finally, despite using disposable income as opposed to per capita expenditure (the welfare aggregate of choice for official statistics since 2013), the trends observed using both aggregates are remarkably similar, despite differences in levels.

There are some limitations that need to be acknowledged while using data from CHIP for poverty analysis. To the extent possible, we make adjustments to mitigate some of these limitations.

First, the present section uses data on household incomes provided to CHIP by NBS since 2007. This is available at the household level (not individual) and only disaggregated into four types (wages, business, property, transfers). This means that it is not possible to assign to incomes from labor (wages and business incomes) to each of the working household members. On the other hand, the CHIP questionnaire collects information on the economic sector of employment and its respective earnings for each individual and for more than one activity. Yet, the total sum of individual earnings across all household members does not exactly match the data reported by NBS. In what follows, for the round 2007, 2013 and 2018 we apply the share of household labor income by each economic sector (agriculture, industry and services) observed using the CHIP specific variables to NBS total household labor income that we use for defining whether a household's poverty status. A second implication of using the NBS income data is that it is not possible to unpack categories within transfers, and changes in their relative importance across time (pensions, social programs, or remittances). The CHIP questionnaire asks about enrollment in social protection programs only since 2013 onwards (and we use this feature for the last period).

Second, as CHIP is a subsample of the NBS survey, the change in the sampling frame implemented since 2013 represents a break in the series. Until 2012, the sampling frame of the official household survey was based on population registration system (hukou), so permanent migrant households, living in an area other than their

\footnotetext{
${ }^{13}$ Information extracted from Poverty Monitoring Reports over the years. See Annex for further details.
} 
hukou, were by design excluded. Therefore, the 2002 and 2007 CHIP surveys have independently collected its own migrant samples. The analysis below excludes the migrant samples since the objective is to analyze what was officially considered when measuring rural poverty. In 2013, the Integrated Household Survey uses the national 2010 population census as the sampling frame, so that the population covered in CHIP and the IHS is the same. The change in the sampling frame represents a potential challenge for the comparison between 2007 and 2013. Specifically, even in the absence of real changes, part of the income from migrant workers that was recorded as part of labor income in 2007 would be considered in 2013 as remittances (part of transfer income) since the migrant worker may no longer be considered a household member. Indeed, according to NBS yearbook data, the share of disposable income from transfers among rural households in 2012 was 7.6 percent and jumped to 17.5 percent in 2013 - a difference large enough to suggest that methodological changes are behind it.

To adjust for the changing sampling frame, we implement an adjustment. While we are unable to obtain fully comparable income components, when doing analysis comparing 2007 and 2013, in the 2007 sample we exclude individuals who spent more than 6 months $^{14}$ working outside their local area (village/town) from the rural household members roster, and their income - from the household income. This, we believe, renders employment and earnings information of 2007 round more comparable to 2013 . We impute part of their income as transfers (remittances) accrued to rural households, according to the share of labor income sent to hometown households in the migrant sample of the 2009 CHIP. The share of household members that are reclassified as permanent migrants based on this criterion is 16.8 percent (Figure 11). For robustness, we also include the decomposition results in which such correction is not implemented.

Figure 211. Share of permanent migrants in rural samples

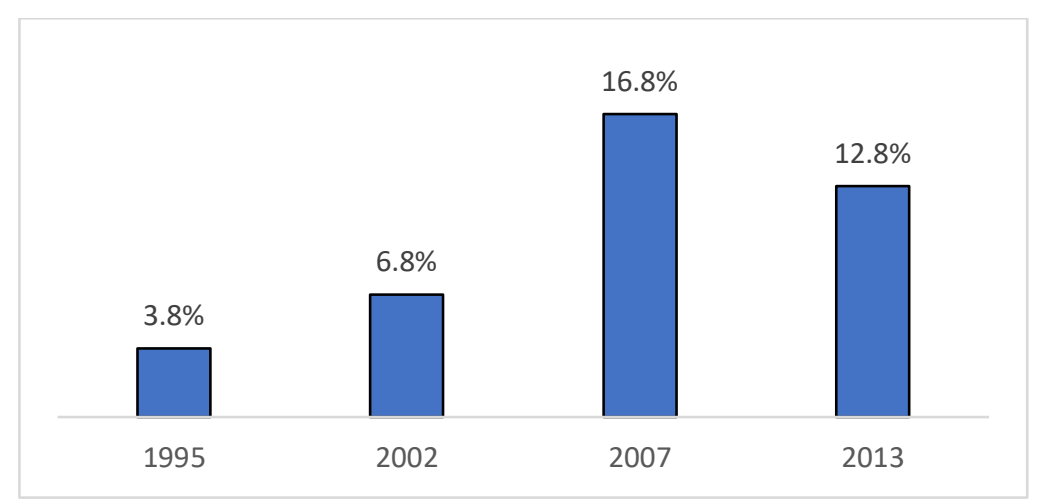

Source: Authors' calculation with CHIP data 1995, 2002, 2007, and 2013. Permanent migrants are defined as those who lived/worked outside of household's village/town for more than 6 months in the year prior to the survey. CHIP 1988 does not provide relevant information to define permanent migrants.

Finally, starting in 2013 the official total disposable income incorporates the value of the rent that households that own their property would have to pay if they did not own the house (imputed rent) as part of the "property income" component. This means that even in the absence of real changes, property income in 2013 would be higher than in 2007. To account for this change, for the 2007-13 comparison of total household income and poverty decomposition, in the 2013 round we excluded the "imputed rent" component.

\footnotetext{
${ }^{14}$ NBS defines migrant workers as those who are engaged in agriculture or non-agriculture activities for more than 6 months outside the township area where they hold the household registration status in rural areas. See link: http://www.stats.gov.cn/ztjc/zdtjgz/yblh/dczsc/201710/t20171010 1540823.html.
} 


\subsection{Overview of results}

This section presents the results from the decomposition exercise throughout 30 years, between 1988 and 2018 . The results are presented distinguishing the five phases described above (Figure 12). The following subsections look in detail in each of the phases, and here we present overall results over the entire period.

In the first three decades of reforms, increased labor opportunities, in terms of increasing productivity, and to a lesser extent, movement across economic sectors, was the main sources of rural poverty reduction. In the early years, within sector income growth, particularly in agriculture, was the most important factor behind poverty reduction. Real earnings per worker in the agricultural sector grew at an annual rate of 8 percent between 1988 to 1995 , and a vast majority of rural workers (more than 4 out of 5) remained engaged in agriculture. Since the mid-1990s, however, increasing income from non-agriculture activities start playing a more noticeable role in poverty reduction, both due to the shift of workers to industry and services (in rural areas or through migration) and to the growth in non-agricultural earnings per worker.

By the late 2000s rural poverty fell below 10 percent and became increasingly concentrated in remote areas in the Western and Central regions. For this groups, further poverty reductions were no longer driven by rising labor incomes but, instead, by the increasing role of private and public transfers. Reallocation of employment out of agriculture and growth of earnings in services among those in the bottom quintile have slowed. But migration to urban areas accelerated, and family transfers (remittances) became increasingly important to the relatively worse-off rural households. In addition, since 2011, the central government strengthened social policy by extending pensions to rural areas and social assistance. These public transfers became increasingly important in 2013-18 to lift the most deprived out of poverty (Figure 13).

Figure 12. Changes in employment structure and average earnings by sectors of rural economy, 19882018

Employment of rural workers, by sector

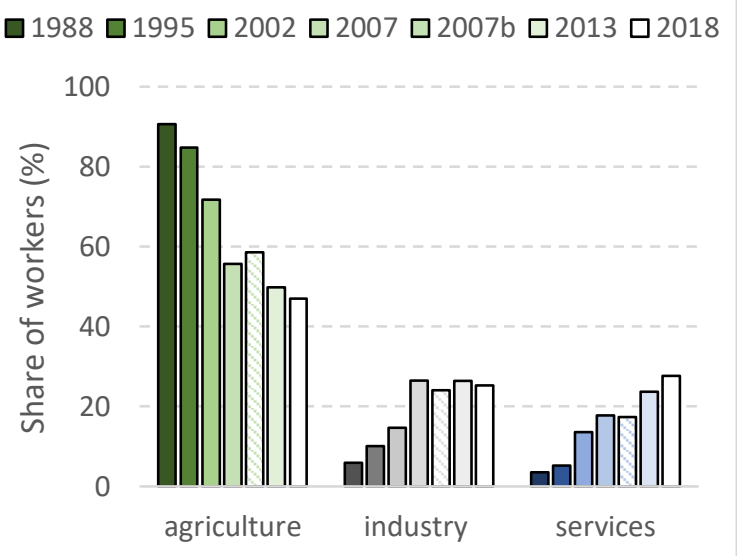

Average earnings per worker by sector

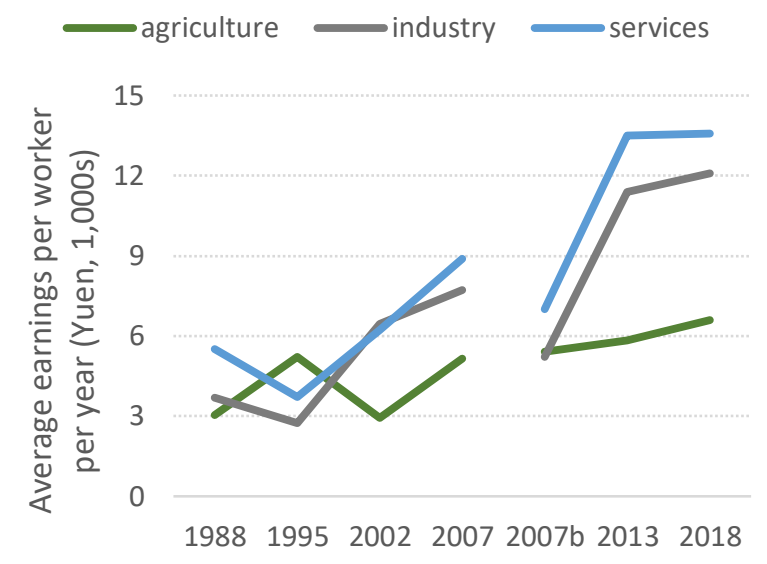

Source: Authors, based on CHIP. 2013-2018 data comes from Zhang and Liang (forthcoming). Note: 2007b refers to the adjusted indicators to consider break in comparability over time, as sampling frame changed from being hukou-based (place of registration) to census-based (place of residence). 
Figure 13. Labor income was the largest driver of poverty reduction until 2013.

Contribution of all sources of income to poverty reduction

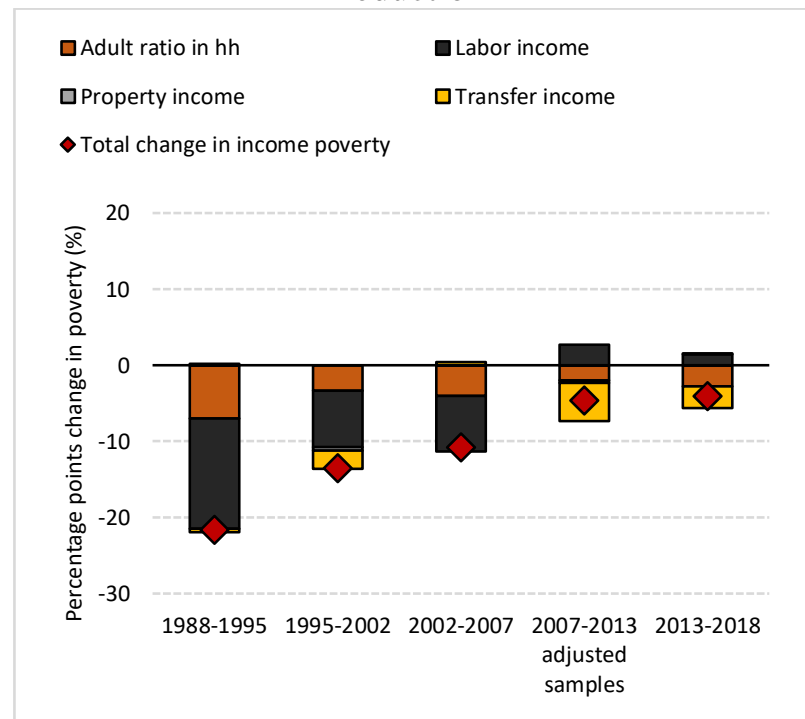

Contribution of labor income to poverty reduction

Source: based on CHIP surveys. 2013-2018 data comes from Zhang and Liang(forthcoming). Note: Shapley decomposition of poverty changes by income sources following Azevedo, Sanfelice and Minh (2012). The figure on the right, decomposes further the labor income component by economic sector. Adjusted samples refer to the adjusted indicators to consider break in comparability over time, as sampling frame changed from being hukou-based (place of registration) to census-based (place of residence).

\subsubsection{First phase: 1978-1995}

The early period of reform and opening-up of the economy (1978-95) is characterized by increasing agricultural productivity and associated fast poverty reduction. The reforms began in the agriculture sector, with the transition from the rural collectives to the Household Responsibility System (HRS). The liberalization of prices for agricultural products in the early 1980s set the stage for an inclusive growth path. The primary sector contributed less than 30 percent of the overall GDP in 1978 but employed almost 70 percent of the labor force. The HRS provided de facto land use rights to households and gradually liberalized farm output and input markets (1978-1984). Grain yield per unit area increased by 42.8 percent, total output of grain increased by 33.6 percent, and real agricultural value-added increased by 52.6 percent. ${ }^{15}$

With almost all of the rural population living in poverty, these high rates of agricultural growth translated into impressive rates of poverty reduction. From 1978 to 1995, the rural poverty rate decreased from 98 to 61 percent according to NBS 2010 standards, with over 200 million fewer poor people at the end of the period. ${ }^{16}$ Ravallion and Chen (2007) and Montalvo and Ravallion (2010) conclude that in the 1980s and 1990s, agriculture was "the real driving force in China's remarkable success against absolute poverty, rather than the secondary (manufacturing) or tertiary (services) sectors" (Montalvo and Ravallion 2010, p. 13). ${ }^{17}$ According to the household data from CHIP, national average agricultural productivity - measured by real earnings per worker-

\footnotetext{
${ }^{15}$ Fang et al. (2018). According to Christiansen (2012), agriculture output growth was largely driven by "land saving technological change (improved seeds, fertilizer use) coupled with the expansion of irrigation, aided by liberalized input and output markets." (p. 20).

${ }^{16}$ Using the standard that was relevant at the time (the 1978 standard), the reduction in poverty between 1978 and 1995 was similarly large: from 30.7 to 7.1 percent of the population, representing a decline in the number of poor by 185 million.

${ }^{17}$ See also Lin (1991, 1992, 1998), World Bank (1992, 2001).
} 
rose between 1988 and 1995 on average approximately 8 percent per year (Figure ). Average earnings per worker also grew for industry and services, but at a slower rate than in agriculture, and mostly favored the urban households.

Figure 14. Earnings per worker rose in all sectors except for rural non-agricultural sectors during 1988-1995

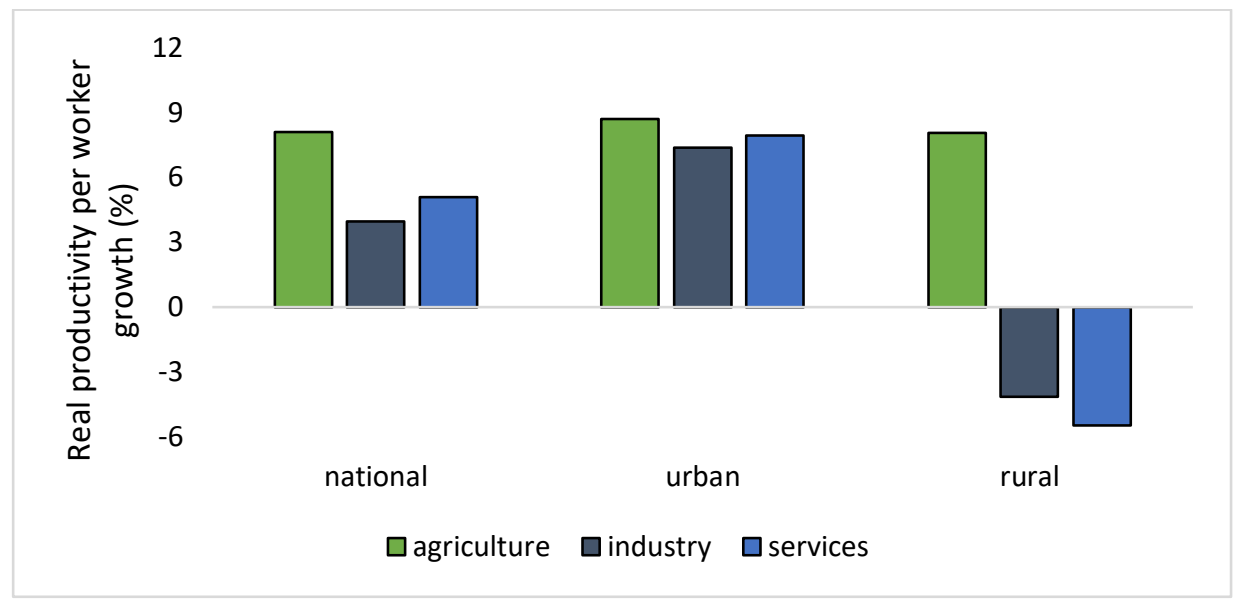

Source: Authors, based on CHIP 1988 and 1995. Note: Labor productivity is approximated as earnings per worker, by sector.

Rural surplus labor was absorbed into non-agricultural sectors thanks to the development of Township and Village Enterprises (TVEs) and had not fueled large migration flows. Before early 1990s, Hukou and Food Coupon systems ${ }^{18}$ created high costs for rural-to-urban migration. At the same time, increased agricultural productivity created a large rural labor surplus. The rapid growth of TVEs helped to absorb this surplus, contributing to the diversification of household incomes and, indirectly, maintaining a relatively high-level of capital-to-labor ratio in the urban industrialization process (by employing rural excess labor outside of cities). In 1978, there were only about 1.5 million TVEs, among which a substantial portion (one third of total) was still in agricultural sector but over a half were in industry. Within one year from 1983 to 1984, number of TVEs increased five-fold to 6 million, with 95 percent of the new enterprises coming from non-agricultural sectors. By 1988, 19 million TVEs were registered, with 0.2 million in agriculture, 7.3 million (39 percent) in industry, 3.7 million (20 percent) in transportation, and 6.2 million (33 percent) in wholesale and retail trade (China Labor Statistical Yearbook 2003). Total employment in TVEs increased from 28 million in 1978 to 123 million by $1992 .{ }^{19}$ Since 1978 TVEs generated more than 130 million jobs and their contribution to rural employment increased from 9.2 to 27.6 percent (Gan 2003).

Farmers who made the first move away from agriculture sustained income growth through employment diversifications and the development of TVEs. By 1988, a quarter of the workers in the richest quintile in rural areas were employed in industry or services, whereas less than 10 percent did so among workers in the poorer quintiles (Figure, panel a). Between 1988 and 1995, rural workers continued to shift from agriculture to industries and services.

Alongside employment movement across sectors, agricultural productivity, measured by agricultural income per farmer, kept improving across all income segments of the rural population. The increase in agricultural

\footnotetext{
${ }^{18}$ The Food coupon system was part of the commodity rationing systems, that allowed households purchase foodstuff. The system was introduced in the mid-1950s, in the central-planning period. Ultimately, it created high transaction costs for relocating from rural to urban areas and across provinces, since the coupons were given according to residence status.

${ }^{19}$ Freije et al. (2019).
} 
productivity resulted from a combination of several attempts during the years to liberalize the state procurement systems, as well as positive returns to massive irrigation investment made in the previous two decades. ${ }^{20}$ There was also considerable effort to spur the development of agricultural research and extension and connect it better to farming practices. On the other hand, rural industry and services productivity remained low (compared to urban) and grew sluggishly during the subsequent period from 1988 to 1995 (Figure, panel b).

Agricultural productivity and employment diversification contributed the most to rural poverty reduction in this period. Between 1988 and 1995, rural poverty fell 22 percentage points from 61 to 40 percent. ${ }^{21}$ Decomposing this poverty changes by income source, it is clear that the main source of poverty reduction was increases in labor incomes, in particular, from agriculture (Figure, panel c). Agricultural earnings per worker was the main driver of poverty reduction. Consistent with what was observed in panel $\mathrm{b}$ agricultural earnings per worker (akin to productivity) rather than changes in the number of workers employed in the sector led to this labor income growth.

Demographic dividend also worked in favor of poverty reduction. After more than a decade of fertility decline, rural dependency ratio fell significantly for all income groups in this period (Table 3). Out of the 22-percentage point reduction in poverty between 1988 and 1995, favorable demographic structure contributed 7 percentage points, and was the second largest contributor to poverty reduction after labor incomes.

Figure 3. Rural sectoral changes in employment, productivity, and contribution to poverty reduction 1988-1995

a. Share of employment by sector and household quintiles. 1988 and 1995.

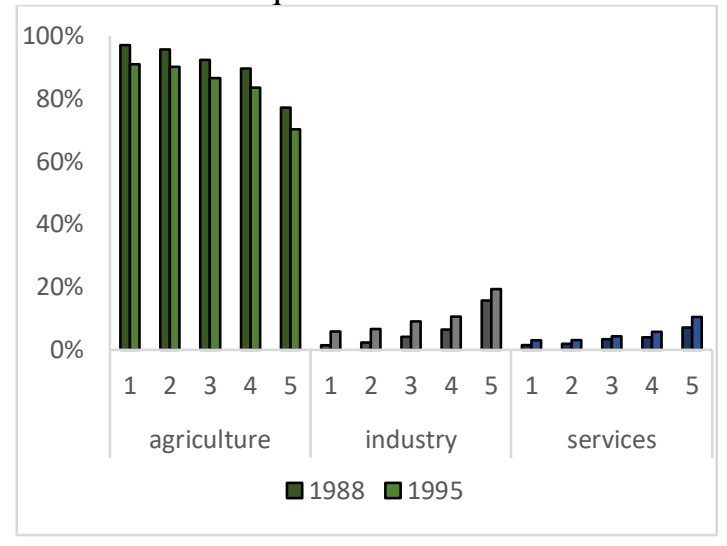

b. Earnings per worker, by sector and household quintiles. 1988 and 1995.

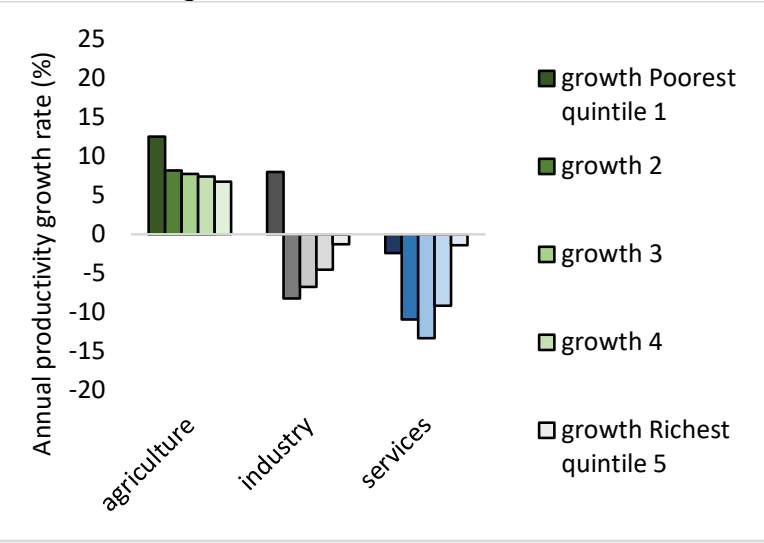

\footnotetext{
${ }^{20}$ Fan and Hazell (2001).

${ }^{21}$ Estimate based on CHIP data using per capita disposable income. NBS official rates are 74 in 1990 and 60 in 1995 . No estimate for 1988 using the 2010 standard is available.
} 
c. Decomposition of poverty changes. 1988-95.

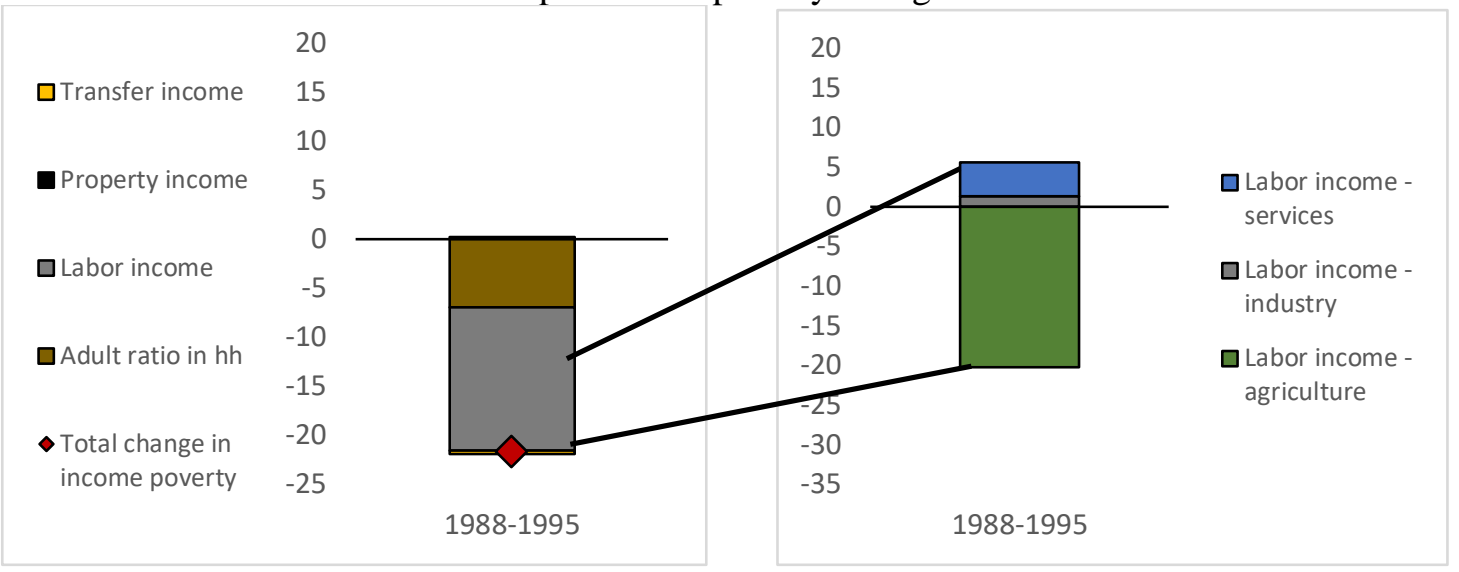

Source: Authors, based on CHIP 1988, 1995. Quintiles are of the rural distribution of per capita household income. Note: Shapley decomposition of poverty changes by income sources following Azevedo, Sanfelice and Minh (2012). 'Adult ratio in household' is the share of household members 14 and above over the total household size as a large share of elderly in rural areas continued to work past 65. The figure on the right, decomposes further the labor income component by economic sector.

\subsection{Second phase: mid-1990s to early 2000s}

In a second phase starting in the mid-1990s to early 2000s, the non-agricultural rural economy prevailed over agriculture for the first time to become the main driver of poverty reduction. After almost two decades of productivity boom in agriculture there was increasing surplus labor in rural areas, and workers were increasingly moving to opportunities in industry and services, seeking higher returns and diversification of the incomegenerating activities. The late 1990s marked the deepening of market-oriented reforms of TVEs and StateOwned Enterprises (SOE). The urban implementation of this agenda featured large SOE reforms. Instead, the rural implementation was characterized by the massive privatization of TVEs, mostly concentrated in nonagricultural sectors. ${ }^{22}$

These reforms became the pulling factors that accelerated the movement of labor away from agriculture into non-agricultural sectors. According to CHIP data, the share of employment in agriculture in rural areas declined from 85 percent in 1995 to 72 percent in 2002, as industry and services gained importance. While agriculture remained the main source of incomes for rural households, poorer rural workers began engaging in nonagriculture activities. By 2002, 30 percent of rural employment, and on average one half of total household incomes was related to non-farm activities.

The deepening of the reforms also speeded up non-agricultural productivity growth across the distribution. The revitalization of input and output markets, and introduction of more competition in the economy, boosted productivity growth in the non-agricultural sectors. During this period, earnings per worker in rural industry increased over 15 percent per year, and over 3 percent in services (Figure, panel b), suggesting improvements in labor productivity. However, with the state procurement price system still in place, agricultural sector lagged in this wave of reforms and its productivity seemed to take a halt. Contrasted with robust growth of employment in services sector across all quintiles, industry employment among the richest rural households began to level off in this period, signaling more productive options in either rural services or urban sectors. These movements at the household level coincided with the development of service sector TVEs. The number of TVEs in industry

\footnotetext{
${ }^{22} \operatorname{Li}(2003)$.
} 
remained almost constant around 6.7 million from 1998 to 2002, but TVEs in services such as in wholesale and retail trade increased from 5.5 million in 1998 to 6.3 million in $2002 .{ }^{23}$

Growing engagement and productivity in non-agriculture sectors contributed the most to reduction in rural poverty in this second phase. From 1995 to 2002, the rural poverty rate dropped from around 40 to 26 percent, allowing the richer half of the $2^{\text {nd }}$ income quintile to escape poverty. Despite the temporary setback in the agricultural sector, growth in labor income remained the single most important driver of poverty reduction, accounting for half of the total reduction (Figure, Panel c). Among the labor incomes, industry and services incomes were equally important in reducing poverty, whereas agricultural income (with lower share of workers and lower earnings per worker) did not seem to help (Figure, panel c).

Favorable demographic structure and transfer income also supported rural poverty alleviation, but to a lesser extent compared to labor income. Change in the share of adults among household members contributed a little more than a tenth of overall poverty reduction. Transfer incomes also helped poverty reduction, either through increased private transfers (remittances) or greater public transfers. The increase in the share of household members who spend more than six months working outside their local residence (shown in Figure 2 above) suggests that remittances may play a predominant role within this component. As 2002 survey had significantly more consistent income questions than 1995 between total household income and the sum of subcomponents (bringing it closer to 10 percent in the third and fourth quintile), the measurement component is minor and is seen as contributing to poverty reduction. ${ }^{24}$

\footnotetext{
${ }^{23}$ China Employment Yearbook 2003.

24 This improvement may be partly due to the enhanced partnership with NBS. The household income module in CHIP 2002 rural questionnaire asks the enumerators to fill the survey according to the NBS Rural Household Survey results whenever possible. Even though CHIP did not receive directly the NBS data, this questionnaire instruction hinted that the CHIP enumerators had partial access to NBS data.
} 
Figure 16. Rural sectoral changes in employment, productivity, and contribution to poverty reduction 1995-2002

a. Share of employment, by sector and household quintiles. 1995 and 2002.

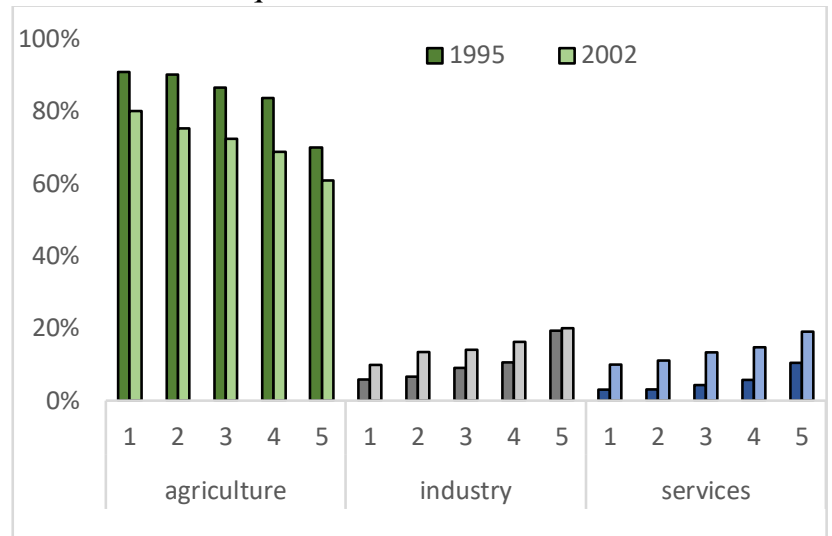

b. Earnings per worker, by sector and household quintiles. 1995 and 2002.

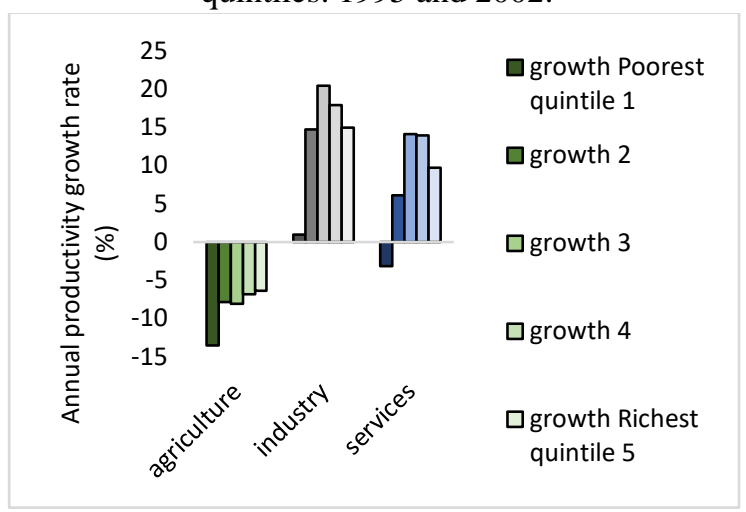

c. Decomposition of poverty changes. 1995-2002.

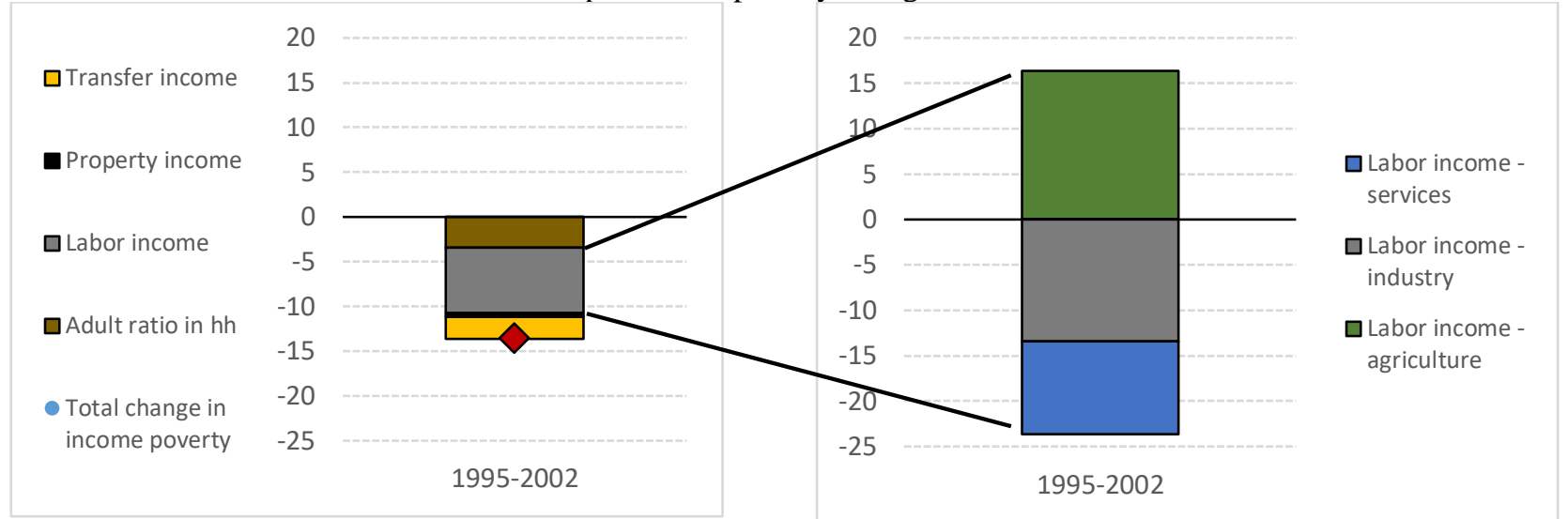

Source: Authors' calucation based on CHIP 1995, 2002. Quintiles of the rural distribution of per capita household income. Note: On decomposition of poverty changes in panel c, see details in Figure12.

\subsection{Third phase: The 2000s}

In the third phase from 2002 to 2007, the economy rode the wave of industrialization and became the "world's factory", which sustained high income growth for both rural and urban households. China became a member of WTO at the end of 2001. During the 6 years between the WTO accession and the global financial crisis of 2008, the Chinese economy grew by more than 10 percent each year. Both industry and services were parts of the engine for this unprecedented period of growth, contributing substantially to overall economy growth, as reviewed in Merotto and Jiang 2021. Domestic demand and, crucially, capital deepening supported this growth. The dividends of integrating into global trade translated into income growth for both rural and urban households. According to NBS Yearbook data, between 2002 and 2007 per capita household income grew by 8 percent in rural areas per year, and 10 percent in urban areas.

Such impressive income growth was shared by the bottom 40 percent, as workers continued to shift out of agriculture mainly to industrial activities. At the beginning of this period, the rural poverty rate was about 31 percent (2010 standard), according to CHIP data. Over half of the poor households were still engaged in agriculture. With China's WTO accession, industrial employment among workers with rural hukou grew rapidly especially among the poor, through forward and backward linkages with urban markets and increased 
demand for products of labor-intensive industries. ${ }^{25}$ The share of workers engaged in industrial activities among the poorest two quintiles increased by more than 10 percentage points, doubling the rate in the previous period.

The growing importance of non-agricultural employment reflects both the growth of industries and services in rural areas, as well as the increased migration of rural workers to urban areas. At the same time, migration to urban areas for better opportunities, temporary or permanent was rising fast. Both inter- and intra-provincial migration contributed to a steady rise in the migrant population (Giles and $\mathrm{Mu} 2021$ ). In this context, it is important to remember that given that the sampling frame of the survey is based on registration (hukou) rather than residence, it is likely that some of the workers included in these figures spend part of their time working outside their hometown place of residence. The implication is that some, but not all, of the employment shift presented here is associated with increasing importance of rural industrial and service sectors. The rest represents the shift to work outside their hometown.

During this period, within-sector labor productivity in non-agricultural activities was growing fast, especially in services. Among workers in the industry sector, earnings per worker grew on average 5 percent per year across the distribution (Figure, panel b), although at much lower speed than the urban industry sector which grew on average about 15 percent per year (Annex 2, Figure A1.c).

In addition, the growth of earnings per worker in services accelerated, doubling the rate in the previous period. On average, earnings per worker grew annually over 10 percent, with earnings among the poorest two quintiles growing fast at 15 percent per year. As the poorest two quintiles were closest to the poverty line, poverty reduction benefited greatly from this improvement of productivity (Figure, panel c).

Demographics remained beneficial for poverty reduction. Fertility rates in rural areas continued to drop. The reduction of the demographic dependency rate (increase in the share of adults) contributed about a third of overall reduction in poverty (Figure, panel c).

Figure 17. Rural sectoral changes in employment, productivity, and contribution to poverty reduction 2002-2007

a. Share of employment, by sector and household quintiles. 2002 and 2007.

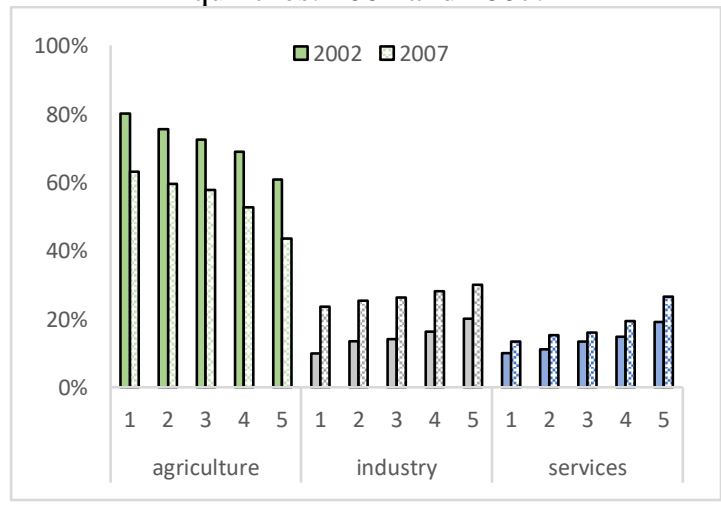

b. Earnings per workers by sector and household quintiles. 2002 and $2007 .$.

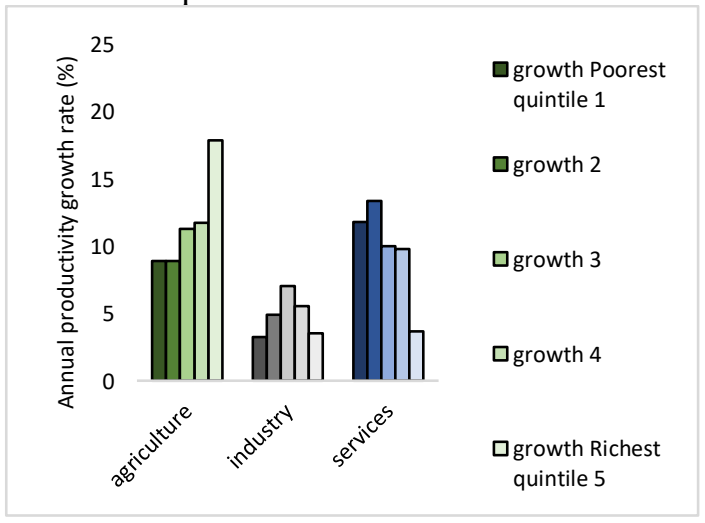

${ }^{25}$ Anderson et al. (2004). 
c. Decomposition of poverty changes. 2007-2007.

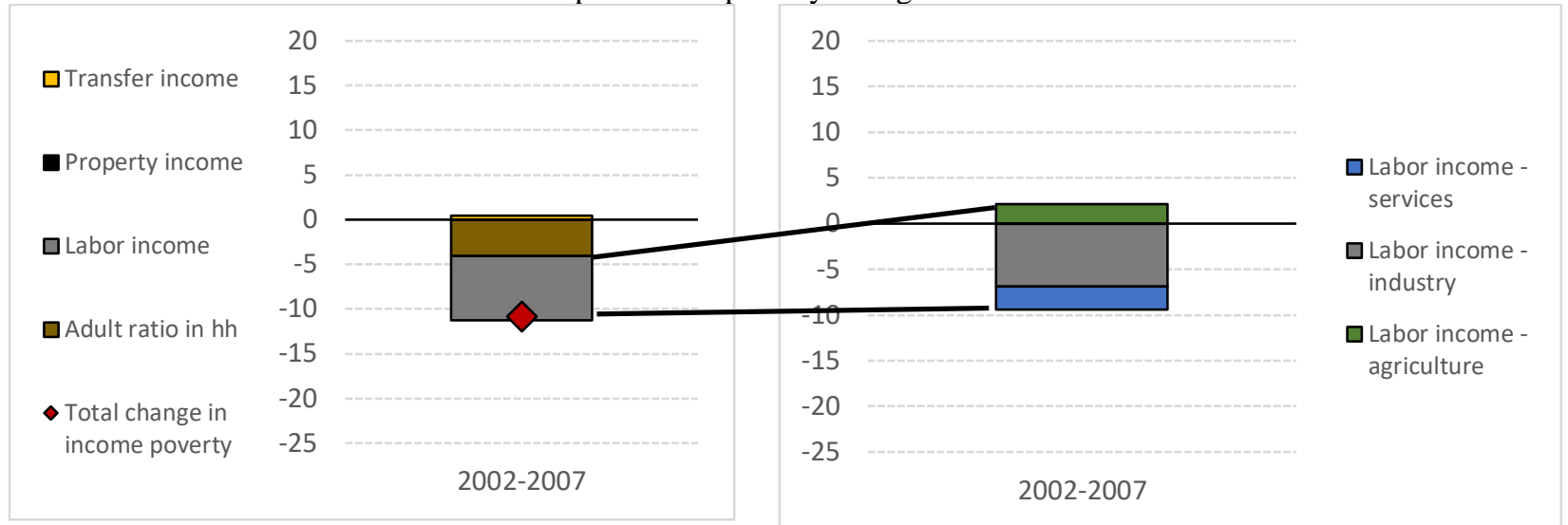

Source: Authors' calculation based on CHIP 2002, 2007. Quintiles of the rural distribution of per capita household income. Note: On decomposition of poverty changes in panel c, see details in Figure 9.

One aspect that was essential to poverty reduction in this period, was the role of regional development. The central government's response to growing regional inequalities, as well as to the 1997 Asian Financial Crisis, was the launch of the Western Development Strategy ("Go West"). The strategy led to an increase in investment in infrastructure and fiscal transfers to western provinces, followed by other programs to support the northern and central regions. ${ }^{26}$ The local governments used these resources to stimulate development of industries, especially labor-intensive manufacturing which shifted its production based in response to lower labor cost in these regions. Regional inequalities leveled off during the 2000s, as growth in the western and central regions caught up with the Eastern region (Figure 18a)

Over the years, as poverty declined rapidly, the contribution of each region to poverty reduction shifted. In 1995-2002 period, there were 79 million. fewer poor people in the Eastern region, contributing to 40 percent of the total poverty reduction. In the subsequent periods, instead, this region represented only 20 percent of overall poverty reduction, while it represented around 45 percent of the total population in the country (Figure 18b)

Figure 18. Regional inequalities

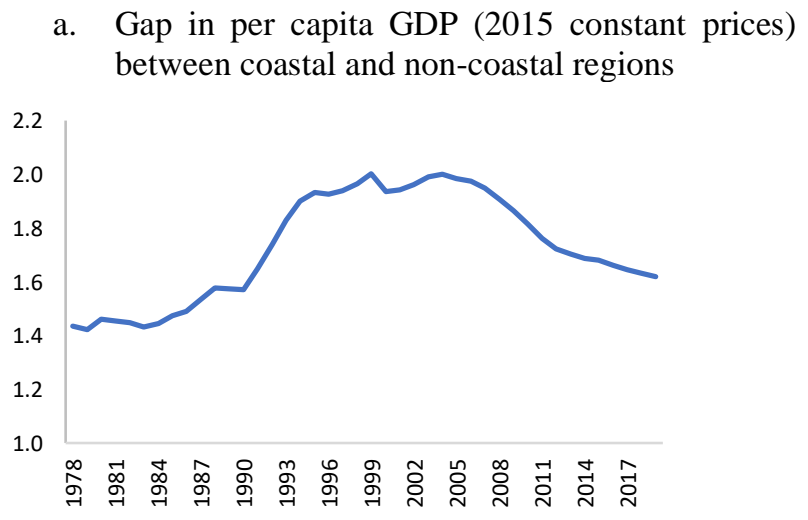

Source: World Bank (2020) China Economic Update, December, based on NBS. b. Regional contribution to poverty reduction. Change in headcount, in millions.

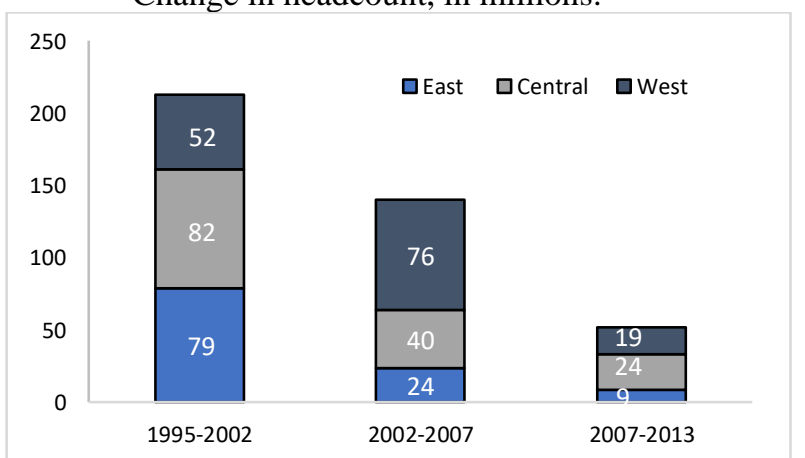

Source: Authors' calculation based on CHIP 1995, 2002, 2007, 2013

${ }^{26}$ Li et al (2013). 


\subsection{Fourth phase: 2007 to 2013}

After a period of rapid industrialization, the fourth phase from 2007 to 2013, began with the global financial crisis and the government's corresponding response to maintain high rates of growth. In September 2008, after the global financial crisis broke out, China's economic growth rate dropped rapidly. Exports showed negative growth, and more than 10 million migrant workers lost their urban jobs by early $2009 .{ }^{27}$ The economy faced the risk of a hard landing.

In response to this crisis, the Chinese government launched a comprehensive package of measures to expand domestic demand and promote growth in November 2008. The package included investment in affordable housing, rural infrastructure and services delivery, transportation networks, educational and medical systems, energy-saving and emission-reducing projects, high-technology industries, post-disaster reconstruction, higher agricultural subsidies and procurement prices, lower tax burden for firms, and credit easing especially for the agriculture sector and SMEs. According to official estimates, the implementation of this package required an investment of about 4 trillion yuan by the end of 2010, equivalent to roughly 4 percent of GDP each year from 2008 to $2010 .{ }^{28}$ High investments helped the economy to maintain a growth of over 8 percent per year in this phase.

Labor shedding from agriculture continued while earnings per worker in non-agricultural sectors continued to grow. With 14 percent of poverty rate at the beginning of this phase, structural changes that happened in the bottom quintile determined the trend of poverty reduction. Between 2007 and 2013, the share of workers in the poorest quintile engaged in agriculture declined by 15 percentage points, from 68 to 53 percent, and two-thirds of them were absorbed by industry, while one-third were absorbed by services. Industry jobs in rural areas took a halt in growth among the richer quintiles (Figure 4, panel a). Earnings per worker among the poorest quintile continued growing in non-agricultural sectors, although at a slower rate than for some of the richer quintiles (Figure 4, panel b). Given the relatively smaller share of labor income due to the reclassification of migrants, and thus their incomes (see footnote 16 for details), among the poorest households, labor income effects ceased to be the main force for poverty reduction in this period.

Incomes from transfers (partly due to re-classification of remittances) took the place of the main driver in poverty reduction. ${ }^{29}$ This is presented in Figure 16, panel 3 as "2007 adjusted sample". Irrespective of whether this adjustment is considered or not, transfers became the main driver of poverty reduction, outweighing the negative contribution of labor incomes (Figure 4, panel c).

Both private and public transfers appear to be playing a role. Unfortunately, given the characteristics of the data publicly available, it is not possible to assess the relative importance of the different components of transfers. However, as reviewed in Giles and $\mathrm{Mu}$ (2021), in this period remittances became an even more important source of family income among rural households. In parallel, central government's latest poverty reduction agenda for 2011-2020 placed more weights on social protection and assistance..$^{30}$ The New Rural Pension Program (NRPP)

\footnotetext{
${ }^{27} \mathrm{Li}(2010)$.

${ }^{28}$ Source: http://www.gov.cn/gongbao/content/2011/content_2020905.htm.

${ }^{29}$ Starting in 2013, there was a change in the sampling frame of the surveys starting in 2013, from being based on registration (hukou) to population census, that is, place of residence. The implication is that permanent migrants previously captured in the rural sample were to be considered part of the urban sample after the methodological change. Their income, which previously was considered as part of household labor income for rural households, no longer will appear as such only part of it, the part that workers would remit to their families, would be reported as part of the household's transfer income. This change represents a survey break. To account for it, we implement an adjustment, described in the methodological section above.

${ }^{30}$ Source: http://www.gov.cn/gongbao/content/2011/content_2020905.htm.
} 
was created in 2009, for rural residents, later integrated into the Urban and Rural Resident Pension Scheme. The program provides unconditional cash transfers for rural elderly aged 60 and above. In 2009, there were 15.6 million beneficiaries, by 2011 it reached 85 million. ${ }^{31}$ In addition, the government extended the reach of the cash assistance program. While urban Dibao was launched in urban areas in 1993 as a direct cash transfer, it was only established in 2003 for rural residents, first in a few provinces and progressively extended to all regions over the years. By 2013, the program reached 59 million beneficiaries ( 29 million households) with an average monthly benefit of 116 yuan per person. ${ }^{32}$ Li et al (2017) using a more disaggregated version of 2013 CHIP (not publicly available) find that in that year private transfers alone reduced poverty by 12 percentage points whereas public transfers reduced it by 4 percentage points (Table 5). Within public transfers, contributory pension scheme and new rural pensions explain half of the differences (that is, 2 percentage points combined).

Demographic changes were also contributing to poverty reduction in this period. Increasing share of adults in the household adds 2 percentage points out to a total 4.6 percentage points reduction in poverty between 2007 and 2013. In the poorest quintile, where poverty reduction happened in this period, the share of children aged 0-14 decreases from 21.8 percent to 18.2 percent. With a significant share of working elderly, the households in the poorest quintile still enjoys a rising demographic dividend. In addition, the slightly rising share of the elderly in the poorest quintile correlates with increasing public transfer income. Studies find that the newly introduced rural pension scheme led to elderly's adult children to migrate and obtain off-farm jobs, ${ }^{33}$ decrease elderly's labor supply, ${ }^{34}$ and improve their health. ${ }^{35}$ Such institutional change favoring the elderly may partly explain the significant contribution observed from the demographic component.

Table 5. The poverty reduction effect from transfer income, 2013

\begin{tabular}{lrr}
\hline & $\begin{array}{r}\text { Poverty } \\
\text { headcount rate }\end{array}$ & $\begin{array}{r}\text { Change in } \\
\text { poverty rate }\end{array}$ \\
\hline Excluding transfer income & $\mathbf{2 4 . 6 7}$ & \\
+ private transfers & $\mathbf{1 2 . 6 9}$ & $\mathbf{- 1 1 . 9 8}$ \\
+ retirement payments & $\mathbf{1 1 . 6 5}$ & $\mathbf{- 1 . 0 4}$ \\
+ new rural pensions & $\mathbf{1 0 . 6 7}$ & $\mathbf{- 0 . 9 8}$ \\
+ other pensions & 10.56 & -0.11 \\
+ minimum living guarantee & 9.92 & -0.64 \\
+ reimbursements & 9.7 & -0.22 \\
+ cash subsidies & 9.5 & -0.2 \\
+ in-kind subsidies & 9.34 & -0.16 \\
+ direct food subsidies & 8.87 & -0.47 \\
+ subsidies for returning farmland to forests and & & \\
grassland & 8.76 & -0.11 \\
+ other policy subsidies & 8.43 & -0.33 \\
\hline Source: Li et al (2017), reprint. & &
\end{tabular}

\footnotetext{
${ }^{31}$ Freije and Zhao (2020).

${ }^{32}$ Freije and Zhao (2020).

${ }^{33}$ Eggleston, Sun and Zhan (2018).

${ }^{34}$ Shu (2018).

${ }^{35}$ Cheng et al. (2018).
} 
Figure 4. Rural sectoral changes in employment, productivity, and contribution to poverty reduction 2007-2013

a. Share of employment, by sector and household quintiles. 2007 and 2013.

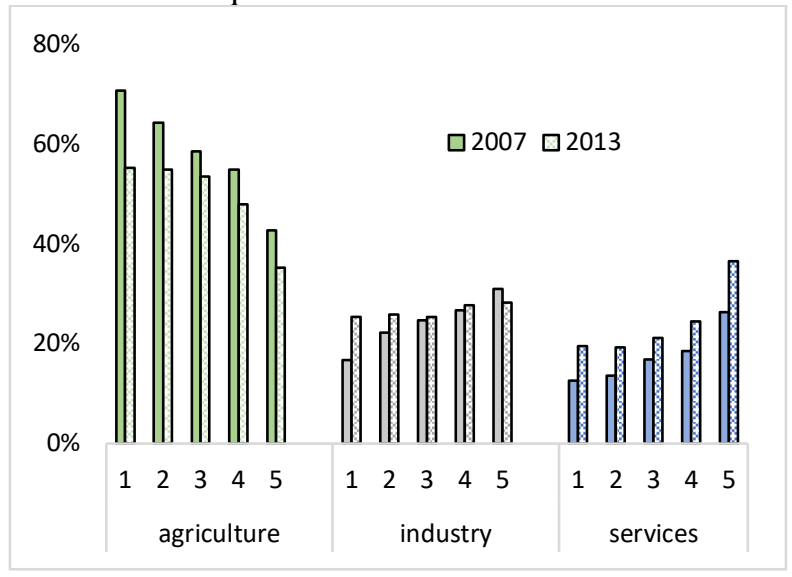

b. Earnings per worker, by sector and household quintiles. 2007 and 2013.

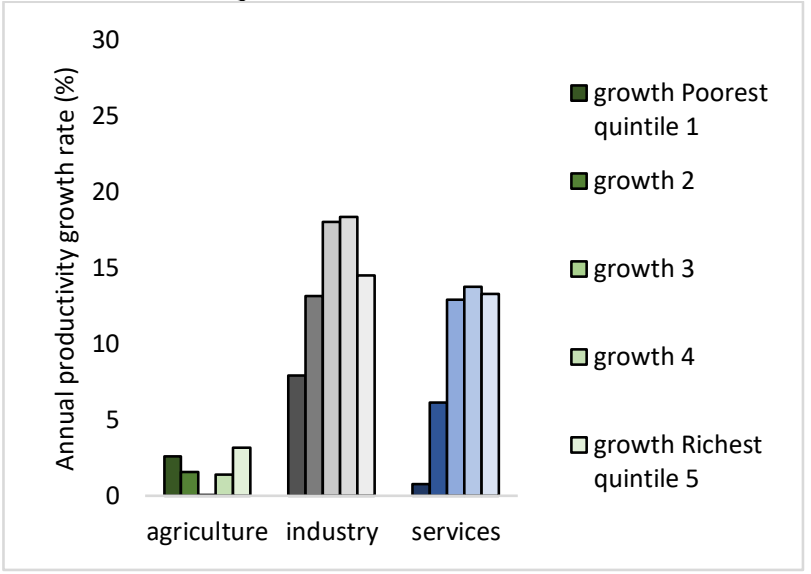

c. Decomposition of poverty changes. 2007-2013.

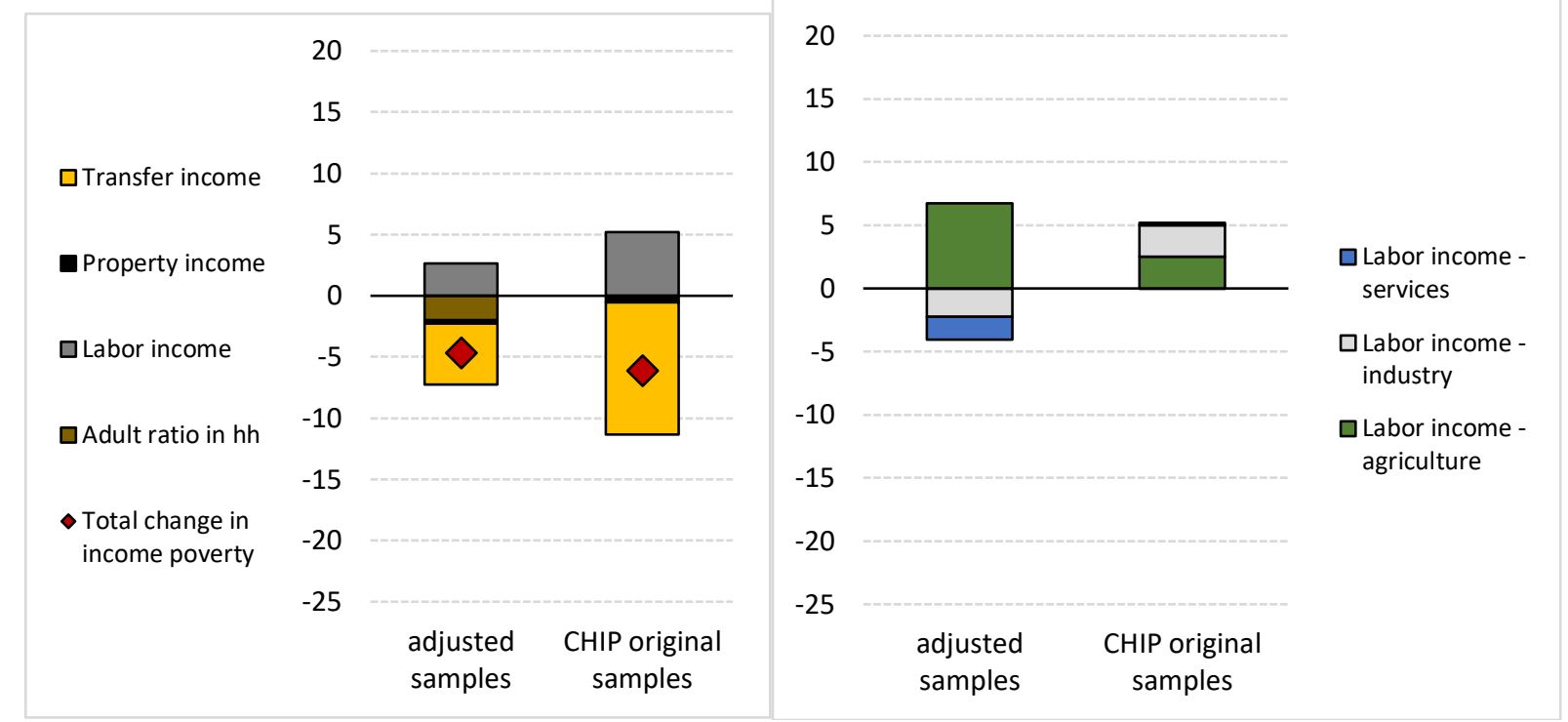

Source: Authors' calculation based on CHIP 2007 and 2013. Quintiles of the rural distribution of per capita household income. Note: See data section for methodological details to ensure comparability across 2007 and 2013.

\subsection{Fifth phase: From 2013 to 2018}

As welfare continued to improve and rural poverty is increasingly concentrated in a smaller part of the population, labor incomes almost vanished in this period as an engine of poverty reduction. The poverty strategy launched in 2011 ('Outline for Development Oriented Poverty Reduction for China's Rural Areas'), introduced an increased poverty threshold of 2,300 RMB per year (the '2010 Poverty Standard') and set the goal of the eradication of poverty by 2020. By 2013, official poverty rate, based on this new standard, had fallen below 10 percent. The remaining poor live in remote areas, less linked to market economy. Therefore, while the economy continued to grow strongly at around 7 percent per year during this period, eradicating poverty required a much 
more explicit and targeted approach. ${ }^{36}$ In this period growth slowed down to single digit. On November 23 , 2020, the government announced that it had reached its goal of elimination of rural extreme poverty. ${ }^{37}$

Rural workers remained largely engaged in agriculture where earnings had ceased to grow. Among those in the bottom quintile, employment in agriculture continued at a same rate, while services absorbed workers from shrinking rural industry employment. By 2018, half of rural workers in this group perform agricultural activities, while the rest are equally divided in manufacturing and services (Figure 5, panel a). Between 2013 and 2018, earnings per worker grew significantly less than in the previous period, except for the poorest engaged in nonagricultural activities (Figure 5, panel b). Given lower and declining productivity of agriculture, incomes from this sector represented only 40 percent of total labor income.

Almost half of poverty reduction in 2013-18 was driven by increasing incomes from transfers, particularly public transfers (Figure 5, panel c). Among the bottom quintile in rural areas, income from public transfers grew faster than the rest of the income components (Figure 6). As a result, the share of total household income from public transfers doubled, from 10 in 2013 to 20 percent in $2018 .{ }^{38}$ Similar increases are found in the 5-9 percentile - the relevant group in terms of poverty reduction in this period. All subcomponents of public transfers contributed to this increased income, as the share of households receiving any of them rose significantly across most categories (Figure 6). This result is consistent with what was reported above based on aggregate administrative data reported above (Freije and Zhang, forthcoming). To note, private transfers (largely, remittances) among households in the bottom quintile did not grow over this period, as the share of households receiving such transfers declined dramatically, from around half of households to just over a quarter of them (as documented also by Giles and Mu, forthcoming).

\footnotetext{
${ }^{36}$ China's targeted poverty strategy during the last decade was aimed at achieving zero poverty by 2020 . Resources allocated to antipoverty programs more than doubled between 2011 and 2017. The strategy relied on a "Precise Poverty Alleviation" approach. This approach included identification of poor households, targeted assistance, and assessment of results. Key to the approach was the creation of a National Poverty Registry, a census of poor households with their family characteristics, income sources and their needs. Initially, the census contained 128,000 villages (of about 600,000 villages in China) and close to 90 million individuals.

37 See, State Council 2021. Poverty Alleviation: China's Experience and Contribution. The State Council Information Office of the People's Republic of China. https://apnews.com/article/china-celebrates-end-extreme-poverty-1449b5dc8a484883af847f4c38f64c326

${ }^{38}$ Similar results are reported by official data for all rural households (not only the poorest). Per capita income from transfers in 201318 grew at 12.3 percent per year, compared to 9.3 percent for total disposable income. As a result, incomes from transfers among rural areas grew to represent 20 percent of total disposable income by 2018, from 17.5 percent in 2013 .
} 
Figure 5. Rural sectoral changes in employment, productivity, and contribution to poverty reduction 2013-2018

a. Share of employment, by sector and household quintiles. 2013 and 2018.

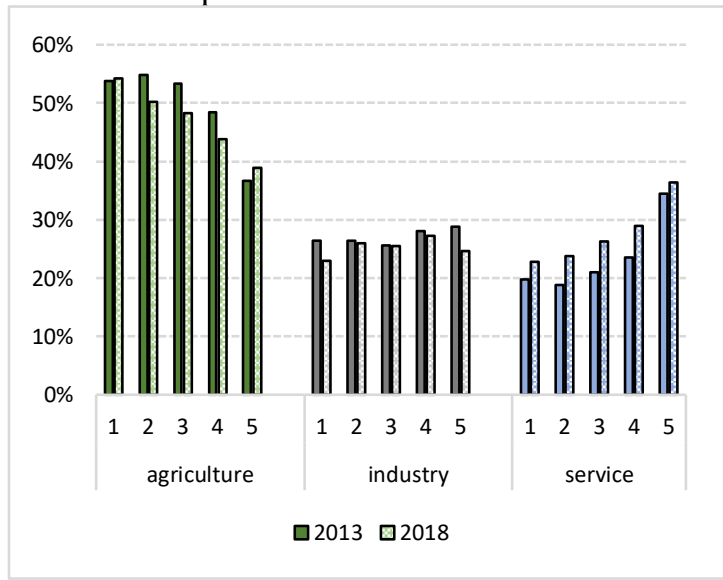

b. Earnings per worker, by sector and household quintiles. 2013 and 2018.

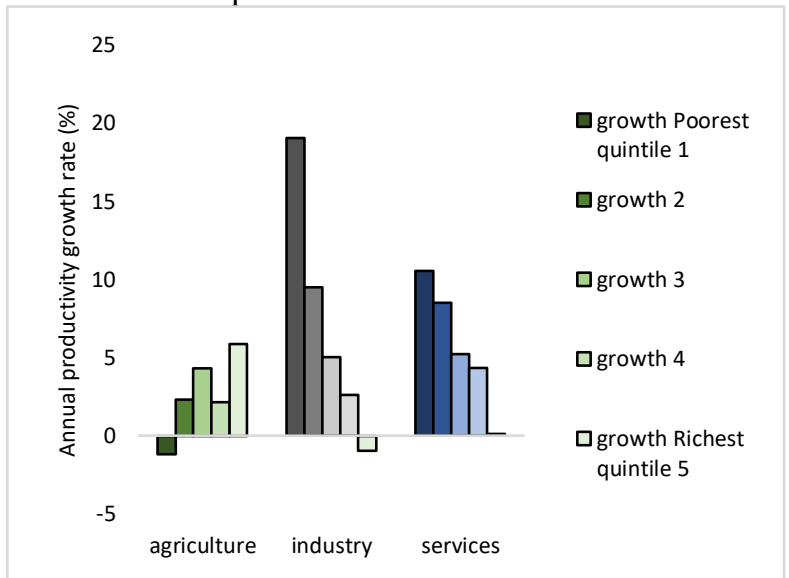

c. Decomposition of poverty changes. 2013-2018.

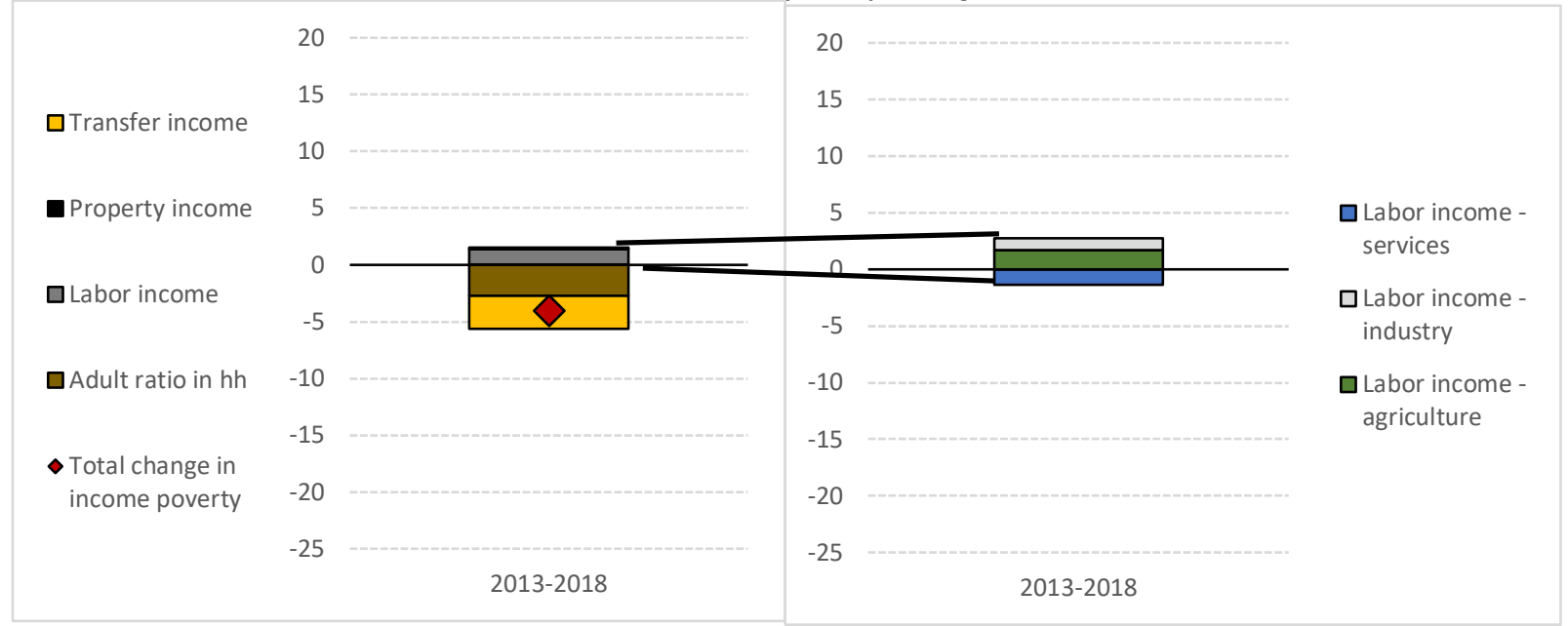

Source: CHIP team's calculation Zhang and Liang (forthcoming)Quintiles of the rural distribution of per capita household income. Note: On decomposition of poverty changes in panel c, see details in Figure 12.

Finally, demographics continued to matter for poverty reduction, and increasingly so. An increasing share of adults in the household made an equally large contribution to poverty reduction as did increased transfers. As in the previous periods, the share of children in the households continued to decline through 2018, resulting in a higher share of potential income earners. Taken together, this component contributed one-half of poverty reduction in the period. 
Figure 6. Among the poorest households, income from public transfers grew faster than other income components of disposable income, particularly from pensions and health reimbursement

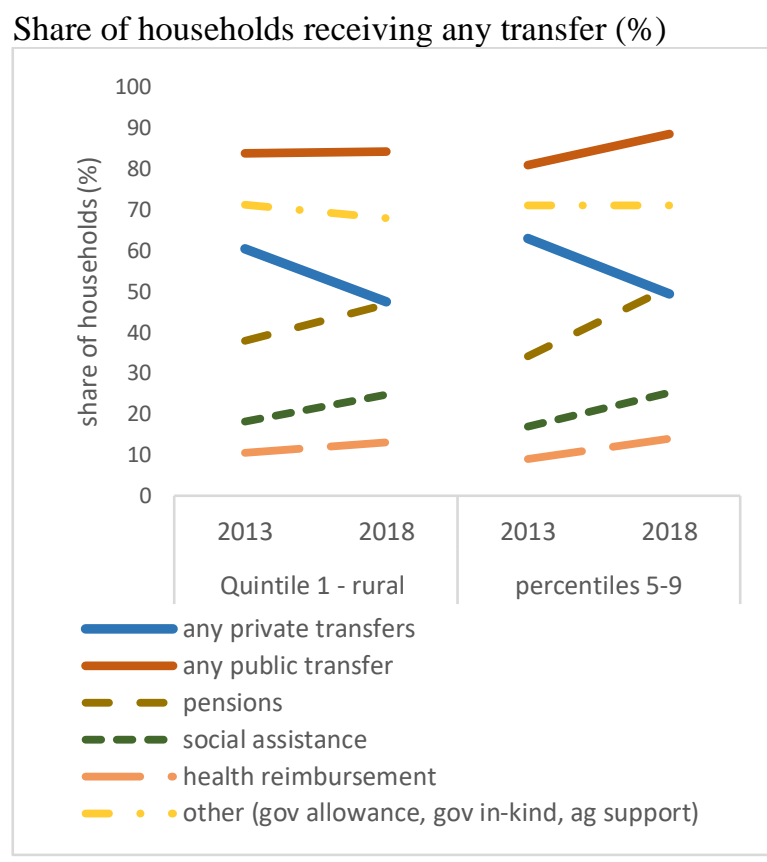

Source: CHIP 2013 and 2018. Zhang and Liang (forthcoming)
Per capita income from transfers (annual, 2011 prices)

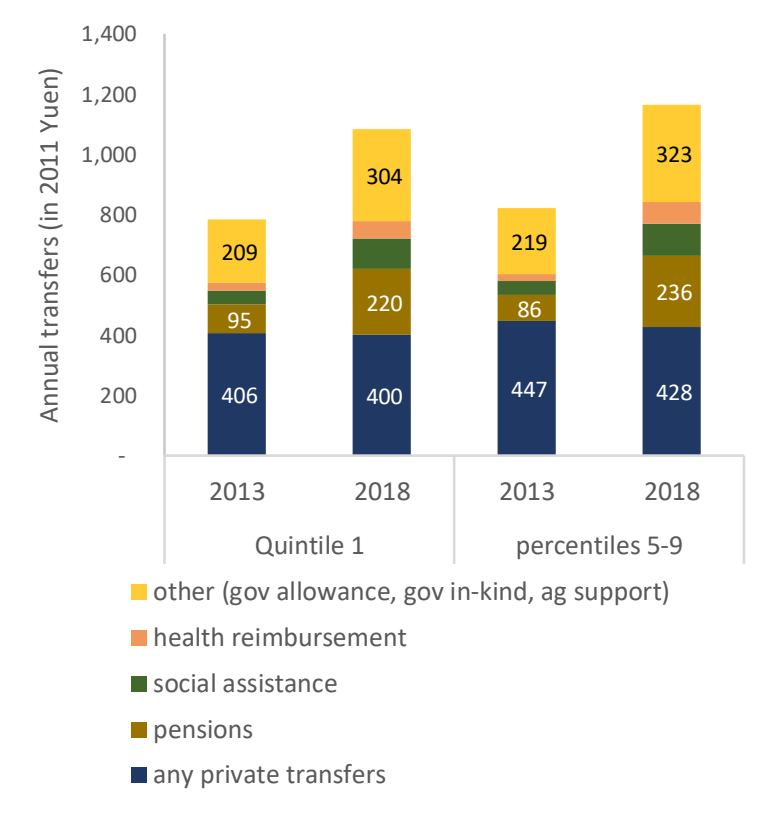

\section{Implications of the findings for poverty reduction in China}

By looking in detail at the channels of China's poverty reduction experience over the past four decades, two main findings with a bearing on the future agenda for poverty reduction emerge.

First, economic transformation and rapid growth, by providing better paying jobs and increasing labor productivity, were the major force behind China's poverty reduction since the 1980s, but with changing roles of different sectors. Starting from very high poverty headcount rates (over four-fifths of the total rural population), broad-based labor-intensive growth in agriculture was initially the main driving force, followed by the expansion of non-agriculture sectors since the 2000s and rapidly increasing productivity and earnings. Subsequently, as the country's poverty rate approached 10 percent, transfers from migrant workers as well as public transfers, became the major force to reduce it even further, resulting in the near elimination of extreme rural poverty. In addition, demographic benefits of fertility transition with falling dependency rates played a supporting role in poverty reduction.

Second, the process of economic transformation has not completely run its course. The benchmarking of China versus other economies at its economic development level in a number of studies shows that the shares of employment and GDP in agriculture remain very high, while the rate of urbanization is low, especially in large mega-cities. There is still a potential for further productivity gains via reallocation of labor across sectors and locations. Combined with the increased standard of what is considered as subsistence minimum in China, 
congruent with its current development level, ${ }^{39}$ the agenda for future poverty reduction past elimination of extreme poverty (defined by 2010 standard) calls for reflection on what the lessons from the past herald for the future agenda.

Based on the study of the past four decades, and with an eye of what is to come, three main reflections emerge.

First, as the country adopts higher poverty standards, poverty reduction will again become an inclusive growth agenda. According to the US\$ 5.50 per person per day (in $2011 \mathrm{PPP}$ ) poverty line, typical of upper middleincome countries such as China, almost a quarter of the population is poor (Figure 1). As it did in the past, lifting people out of poverty going forward will largely depend on sustained and widely shared growth. At this higher line, almost a third of poverty reduction in rural areas between 2007 and 2018 was due to increases in labor incomes (Figure 7). Data for 2018 show that the poor at this line are mostly working age and have secondary education or more. Nationally, based on a \$5.50/day line, almost two-thirds of the poor are in rural areas while the rest are urban. Therefore, the emphasis on rural revitalization should be complemented with efforts that support job creation more broadly across the country, as the poverty reduction agenda expands to include the urban poor.

Second, inequality can become again a drag not only on the inclusiveness of growth but also growth itself. As shown, growing inequality in the 1990s and 2000s explained the relatively lower ability to turn growth into poverty reduction in China. As inequality tempered since 2008, changes in the distribution have contributed to poverty reduction alongside growth for the first time in decades. Yet, more recent data suggest a new surge of inequality may have begun again -albeit it is early to know whether it represents a halt in inequality reduction or a more permanent new turn of the trend (Figure 23). ${ }^{40}$ In addition, a Gini value of 46.5 is high by international standards, well-above OECD countries and close to traditionally highly unequal countries such as Mexico.

Figure 7. Contributions to rural poverty reduction at higher poverty line

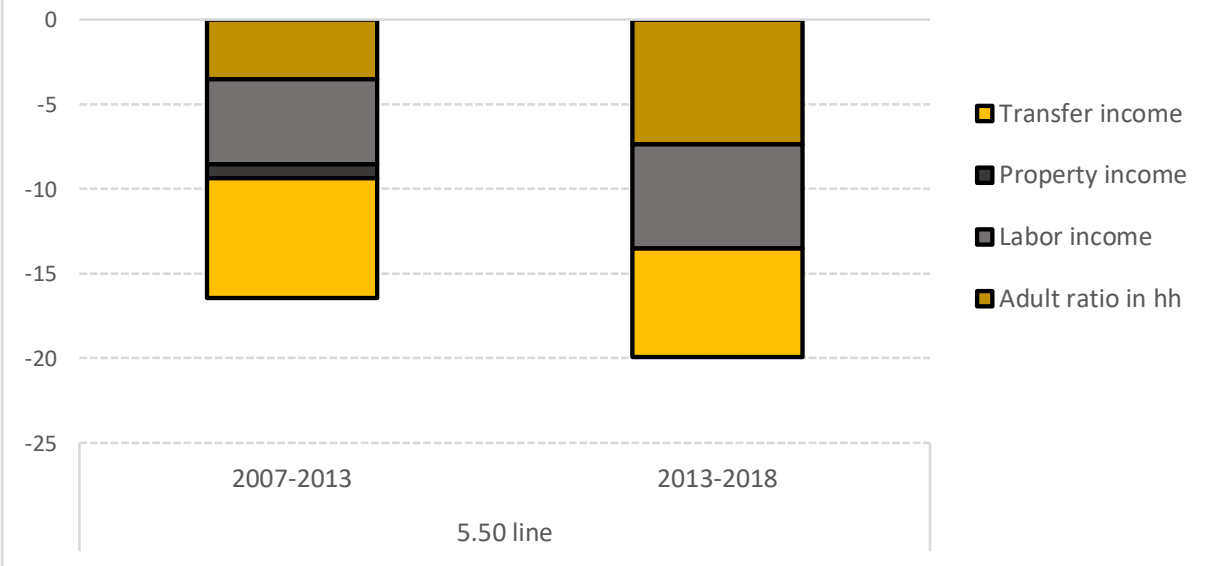

Source: Authors' and CHIP team's calculation based on CHIP 2007, 2013, and 2018 data. $\$ 5.50$ per person per day (in 2011 USD PPP) is international poverty lines typical of upper-middle income countries.

Going forward, reducing inequalities in accessing quality public services as well as easing constraints on labor mobility will remain key. With the concerted effort on narrowing the gaps across individuals, more attention may be given to the barriers that may exist for children to access services of equal quality, irrespective of their

\footnotetext{
${ }^{39}$ As documented in Ravallion and Chen (2020) as countries grow, their poverty standards increase. China is no exception, and the history of revisions in official poverty line methodology fit perfectly into this global pattern.

${ }^{40}$ As documented in World Bank (2020), the impacts of the COVID-19 pandemic and mitigation measures are likely to widen the inequalities, as relatively poorer workers in the informal economy have been particularly strongly affected.
} 
conditions at birth. Closing gaps in access to quality public services will be essential to ensuring increased mobility for future generations. In addition, progressive tax systems can play an important role in addressing inequality and relative poverty, as they do in OECD countries. A recent study showed that personal income tax in China is, indeed, equalizing. But its effect on inequality is minor, compared to that of social contributions and direct transfers, and almost reversed by the unequalizing effect of indirect taxes (value added and consumption taxes).$^{41}$ Compared to other countries, progressive personal income tax accounts for only 5 percent of revenue in China, while yielding close to 15 percent on average in the OECD.

Figure 8. Inequality in China remains high by international standards

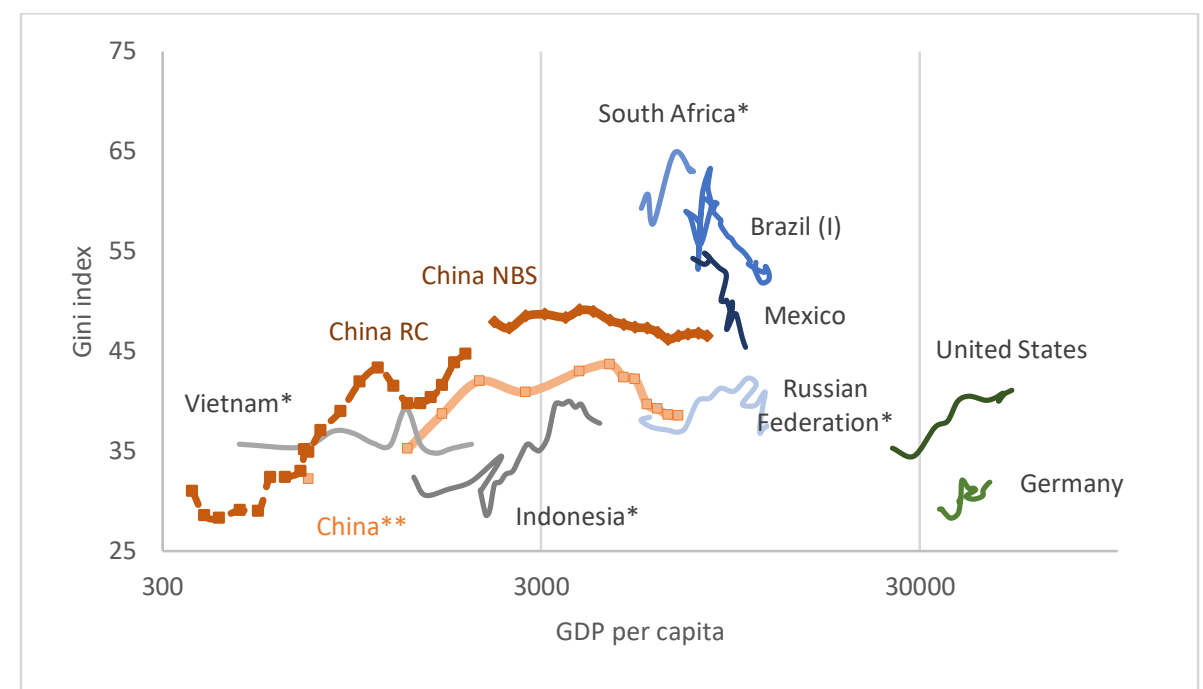

Source: WDI (China consumption inequality and rest of the world); China NBS (income inequality) for 2001-2019 and

Ravallion and Chen (2007) for China for 1981-2001 period (income inequality).

Note: * indicates that Gini coefficient is based on consumption. All other series are based on income.

Finally, a more integrated social protection system may be able to better protect households from shocks, assist in restructuring of the economy towards decarbonization, and moderate inequality in outcomes. Integrating poverty reduction efforts with a revamped social assistance system will be key. Social protection can play a greater role in fostering mobility by ensuring portability across jurisdictions. It can also encourage risk taking among the new entrants to the labor market, helping to sustain small entrepreneurship while protecting against vulnerabilities. While labor income will remain the main driver of well-being, public transfers are becoming an important source of income to the poorest. The recent "precision" poverty targeting built a registry of the poor which is not integrated with the social protection databases, and their management is not always aligned with rapidly changing conditions of livelihood, especially among migrants in urban areas.

The coverage of China's major social assistance programs (DiBao, Tekun, and temporary assistance) is relatively low, with only 56.7 million or about 4.1 percent of the total population registered as beneficiaries. ${ }^{42}$ Moreover, the benefits under these programs are also relatively low and targeting errors are large. Pension coverage, at 85 percent of the labor force, is relatively high but the benefits for some categories of retirees, such as rural residents and informal sector workers, are only a fraction of the poverty line. As a result, a large share of the rural elderly population continues working despite their advanced age. Moving towards a unified, fiscally

\footnotetext{
${ }^{41}$ Lustig and Wang (2020).

${ }^{42}$ World Bank (2020).
} 
sustainable national pension system that provides adequate old age income support is crucial to mitigating risks of old-age poverty especially against the backdrop of China's rapidly aging population.

\section{Conclusions}

In this paper, using official NBS survey-based statistics for 1978-2019 and research-initiated representative household survey data (CHIP) with detailed information on incomes and employment spanning 1988-2018, we document China's massive progress in poverty reduction.

Using PovcalNet data on a group of comparable countries to estimate growth-poverty elasticities, we find that China's sustained fast growth made its poverty reduction record stand out. Until the 2010s, changes in inequality attenuated the impact of growth on poverty. The shocks and economic transformation resulted in an uneven process across time, even though over time China managed to maintain positive growth rates for all income groups.

We study which channels and income sources mattered the most at various stages by applying a decomposition framework developed by Barros et al (2006) and expanded by Azevedo el at (2013) to multiple rounds of Chinese Household Income Project (CHIP) surveys conducted in 1988, 1995, 2002, 2007, 2013 and 2018. We use the poverty line anchored in the latest official definition (2010). We find that economic transformation and rapid growth, by providing better paying jobs and increasing labor productivity, coupled with increasing migration flows in response to that growth, have been the major forces behind China's rural poverty reduction since the 1980s, but with changing roles of different sectors over time. Broad-based labor-intensive growth in agriculture was initially the main driving force, followed by the expansion of non-agriculture sectors since the 2000s and rapidly increasing employment and productivity across the distribution. As the country's poverty rate approached 10 percent by 2007, transfers from migrant workers as well as public transfers became the major drivers of further rural poverty reduction. This process also features the important role of the demographic transition in supporting poverty reduction.

Based on these findings, we propose several reflections for a forward-looking agenda. As China's living standards continue to rise, the official definition of poverty will have to adjust to the higher minimum. With these higher standards, continued structural transformation and an inclusive growth agenda retain crucial importance for sustained poverty reduction. 


\section{References}

Anderson, Kym, Jikun Huang, and Elena Ianchovichina. 2004. "Will China's WTO accession worsen farm household incomes?" China Economic Review 15.4: 443-456.

Azevedo, João Pedro, Viviane Sanfelice, Minh Cong Nguyen, 2012. "Adecomp: Stata module to estimate Shapley Decomposition by Components of a Welfare Measure," Statistical Software Components S457562, Boston College Department of Economics.

Azevedo, João Pedro; Inchauste, Gabriela; Olivieri, Sergio; Saavedra, Jaime; Winkler, Hernan. 2013. Is Labor Income Responsible for Poverty Reduction? A Decomposition Approach. Policy Research Working Paper 6414. World Bank, Washington, DC

Azevedo, João Pedro, Atamanov, Aziz. 2014. Pathways to the Middle Class in Turkey: How Have Reducing Poverty and Boosting Shared Prosperity Helped? World Bank Policy Research Working Paper No. 6834, World Bank, Washington, DC

Baye, Francis Menjo. 2006. "Growth and redistribution effects of poverty changes in Cameroon: A Shapley decomposition analysis." Journal of African Economies, Centre for the Study of African Economies (CSAE), vol. 15(4), pages 543-570, December.

Cheema, Ahmed Raza, and Maqbool H. Sial. 2010. "Estimating the contributions of growth and redistribution to changes in poverty in Pakistan." Pakistan Economic and Social Review 48 (2): 279-306.

Chen, Shaohua and Martin Ravallion. 2020. "Reconciling the conflicting narratives on poverty in China" NBER Working Paper 28147.

Cheng, Lingguo, Hong Liu, Ye Zhang, and Zhong Zhao. 2018. "The health implications of social pensions: Evidence from China's new rural pension scheme." Journal of Comparative Economics 46(1): 53-77.

Christiansen, Luc. 2012. The Role of Agriculture in a Modernizing Society: Food, Farms and Fields in China 2030. World Bank.

Datt, Gaurav and Martin Ravallion. 1992. "Growth and redistribution components of changes in poverty measures: A decomposition with applications to Brazil and India in the 1980s", Journal of Development Economics, 38 (2): 275-295.

Eggleston, Karen, Ang Sun, and Zhaoguo Zhan. 2018. "The impact of rural pensions in China on labor migration." The World Bank Economic Review 32.1: 64-84.

Fang, Cai, Ross Garnaut, and Ligang Song. 2018. "40 Years of China's Reform and Development: How Reform Captured China's Demographic Dividend.” In China's 40 Years of Reform and Development, edited by Cai Fang, Ross Garnaut, and Ligang Song, 5-26. 1978-2018. ANU Press.

Fan, Shenggen, and Peter Hazell. 2001. "Returns to public investments in the less-favored areas of India and China." American Journal of Agricultural Economics 83.5: 1217-1222.

Ferreira, Francisco H. G., Shaohua. Chen, Andrew. L. Dabalen, Yuri. M. Dikhanov, Nada Hamadeh, Dean M. Jolliffe, Ambar Narayan, Espen B. Prydz, Ana L. Revenga, Prem Sangraula, Umar Serajuddin and Nobuo Yoshida. 2016. "A global count of the extreme poor in 2012: data issues, methodology and initial results", The Journal of Economic Inequality, Vol. 14(2): 141-172.

Freije-Rodriguez, Samuel and Fuchang Zhao. 2021. "Public Expenditures under the 2011-2020 Poverty Reduction strategy in China." forthcoming 
Freije-Rodriguez, Samuel, Bert Hofman and Lauren Johnston. 2019. Forty Years of China's Reforms, Poverty Reduction and the World Bank. World Bank Policy Research Working Paper Series.

Giles, John and Ren Mu. 2021. "Migration, growth and poverty reduction in China's villages: A retrospective and discussion of future challenges". forthcoming

Gustaffson, Bjorn, Li Shi, and Terry Sicular. 2008. Inequality and Public Policy in China. Cambridge: Cambridge University Press.

Huang, Jikun and Rozelle, Scott. 2002. "The Nature and Distortions to Agricultural Incentives in China and Implications of WTO Accession”. UC Davis, Dept. of Agricultural \& Resource Economics Working Paper No. 02-006

Huang, Jikun, Qi Zhang and Rozelle, Scott. 2008. "Economic growth, the nature of growth and poverty reduction in rural China", China Economic Journal, volume 1.

Iniguez-Montiel, Alberto Javier. 2014. "Growth with equity for the development of Mexico: Poverty, inequality, and economic growth (1992-2008)." World development 59 (C): 313-326.

Kanbur, R., Yue. Wang, X. Zhang 2020. “The great Chinese inequality turnaround,” Journal of Comparative Economics, in press.

Li, Hongbin. 2003. "Government's budget constraint, competition, and privatization: evidence from China's rural industry." Journal of Comparative Economics 31.3: 486-502.

Li, Shi. 2010. "The economic situation of rural migrant workers in China." China Perspectives.2010/4.

Li, Shi, Hiroshi Sato, and Terry Sicular. 2013. Rising Inequality in China. Challenges to a Harmonious Society. Cambridge: Cambridge University Press.

Li, Shi, Peng Zhan, and Yangyang Shen. 2020. "New Patterns in China's Rural Poverty" in Changing Trends in China's Inequality: Evidence, Analysis, and Prospects, eds. Terry Sicular, Shi Li, Ximing Yue, and Hiroshi Sato, Oxford Scholarship.

Lin, Justin Yifu. 1988. "The Household Responsibility System in China’s Agricultural Reform: A Theoretical and Empirical Study.” Economic Development and Cultural Change 36 (3): S199-224.

. 1991. "The Household Responsibility System Reform and the Adoption of Hybrid Rice in China." Journal of Development Economics 36 (2): 353-72.

1992. "Rural Reforms and Agricultural Growth in China." The American Economic Review 82 (1): $34-51$.

Liu, Mingyue, Xiaolong Feng, Sangui Wang, and Huanguang Qiu. 2020. “China’s Poverty Alleviation over the Last 40 Years: Successes and Challenges." Australian Journal of Agricultural and Resource Economics 64 (1): 209-28.

Luo, Chuliang, Shi Li, Terry Sicular. 2020. "The long-term evolution of national income inequality and rural poverty in China" China Economic Review, Volume 62

Lustig, Nora and Yang Wang 2020. "The Impact of Taxes and Transfers on Income Inequality, Poverty, and the Urban-Rural and Regional Income Gaps in China," Commitment to Equity (CEQ) Working Paper Series 93, Tulane University, Department of Economics.

Meng, Lingsheng. 2013. "Evaluating China’s Poverty Alleviation Program: A Regression Discontinuity Approach.” Journal of Public Economics 101 (May): 1-11. 
Merotto, Dino and Hanchen Jiang. 2021. "What was the impact of creating better Jobs for more people in China's economic transformation? What we know and questions for further investigation", Jobs Working paper, Issue 62, The World bank Jobs Group. Washington, DC: World Bank.

Montalvo, Jose G., and Martin Ravallion. 2010. "The pattern of growth and poverty reduction in China." Journal of Comparative Economics, 38(1): 2-16.

Park, Albert, Sangui Wang, and Guobao Wu. 2002. "Regional poverty targeting in China," Journal of Public Economics, vol. 86(1): 123-153.

Park, Albert and Sangui Wang, 2010. "Community-based Development and Poverty Alleviation: An Evaluation of China's Poor Village Investment Program”, Journal of Public Economics, Volume 94, Issues 9-10, October 2010, Pages 790-799.

Ravallion, Martin, and Shaohua Chen. 2007. "China’s (uneven) progress against poverty." Journal of Development Economics, 82: 1-42.

Ravallion, Martin and Shaohua Chen (2021) "Is that Really a Kuznets Curve? Turning Points for Income Inequality in China" National Bureau of Economic Research Working Paper 29199, August 2021

Ravallion, Martin and Monika Huppi. 1991. "Measuring Changes in Poverty: A Methodological Case Study of Indonesia during an Adjustment Period," The World Bank Economic Review, 5(1): 57-82

Riskin, Carl. 1987. China's Political Economy: The Quest for Development since 1949. Oxford University Press.

Rozelle, Scott and Natalie Hell. 2020. Invisible China: How the Urban-Rural Divide Threatens China's Rise. University of Chicago Press

Shapley, L. 1953. "A value for n-person games.” In,Contributions to the Theory of Games, ed. H. W. Kuhn and A. W. Tucker 2. Princeton, N.J.: Princeton University Press.

Shorrocks A.F. 1999. Decomposition Procedures for Distributional Analysis: A Unified Framework Based on Shapley Value. University of Essex and Institute for Fiscal Studies. Mimeo.

Sicular, Terry, Shi Li, Ximing Yue, and Hiroshi Sato. 2020. Changing Trends in China's Inequality: Evidence, Analysis, and Prospects, Oxford Scholarship.

Shu, Lei. "The effect of the New Rural Social Pension Insurance program on the retirement and labor supply decision in China." The Journal of the Economics of Ageing 12 (2018): 135-150.

State Council 2021. Poverty Alleviation: China's Experience and Contribution. The State Council Information Office of the People's Republic of China

Wang, Sangui. 2013. Reducing Poverty through Agricultural Development in China. IDS Bulletin. 44.

World Bank. 1983. China: Socialist Economic Development. Country Economic Memorandum. Washington, DC: World Bank.

World Bank. 1992. China - Strategies for reducing poverty in the 1990s. Washington, DC: World Bank.

World Bank. 2001. China: Overcoming Rural Poverty. A World Bank country study. Washington, DC.

World Bank. 2009. China - From poor areas to poor people: China's evolving poverty reduction agenda - an assessment of poverty and inequality (English). Washington, DC: World Bank.

World Bank. 2018. Poverty and Shared Prosperity 2018: Piecing Together the Poverty Puzzle. Washington, DC: World Bank. 
World Bank. 2019. Balancing Workers' Protection and Labor Market Flexibility in China. Ed. by Achim Schmillen, Dewen Wang and Josefina Posadas. Washington, DC: World Bank.

World Bank. 2020. Leaning Forward - COVID-19 and China's Reform Agenda. Washington, DC: World Bank.

Zhan, Peng and Xiaomin Liang (Forthcoming) "Assessment of targeted anti-poverty measures in China: Evidence from income decomposition”. CIKD Working Papers, DRC.

Annex 1. Official poverty measurement

Most countries have official poverty measures to track progress in welfare among the worse off members of society. Typically, households' income or expenditure is compared to a threshold (poverty line) that is considered to represent the minimum acceptable level of income or consumption that households to fulfill basic food and nonfood needs. People or households are classified as "poor" if their welfare aggregate (either income or expenditure) falls below the poverty line.

In China, since the beginning of the country's history in measuring poverty, poverty has been measured only for rural areas. The welfare aggregate used in poverty measurement has changed over time, as has the value of the poverty standard.

Welfare aggregates used in poverty measurement in China transitioned from using only income from 1985 to 1997, to a combination of income and expenditure from 1998 to 2010, to using only expenditure from 2011 until today under the "2011-2020 poverty reduction guidelines". ${ }^{43}$ The following table collects citable resources from the China Rural Poverty Monitoring Reports:

\begin{tabular}{|l|l|l|l|}
\hline Period & $\begin{array}{l}\text { Welfare aggregate in } \\
\text { poverty measurement }\end{array}$ & Source & Note \\
\hline $1985-1997$ & Income & 2000 report & Income < poverty line \\
\hline $1998-2010$ & Income or expenditure & $\begin{array}{l}\text { 2001 report, 2003 } \\
\text { report, 2004 report, } \\
\text { 2005 report, 2006 } \\
\text { report, 2007 report }\end{array}$ & $\begin{array}{l}\text { (Income < poverty line and } \\
\text { expenditure < 1.5 poverty line) } \\
\text { OR } \\
\text { (Income < 1.5 poverty line and } \\
\text { expenditure < poverty line) }\end{array}$ \\
\hline 2011-2019 & Expenditure & $\begin{array}{l}\text { Report 2015, report } \\
\text { 2016 }\end{array}$ & expenditure < poverty line \\
\hline
\end{tabular}

Three poverty lines (known as poverty standards) have been used over the past four decades. The first poverty line was the 1978 standard of 100 yuan per day per person in the year 1978, set in 1985 (at 206 per year yuan in 1985). This line was yearly updated using rural price inflation. In 2011 USD PPP terms, the 1978 line was

\footnotetext{
${ }^{43}$ http://www.gov.cn/gongbao/content/2011/content_2020905.htm
} 
equivalent to $\$ 0.98$ per person per day (Chen and Ravallion, 2020). The line was designed to be able to afford a food basket of 2,100 calories per person, per day.

In 2008, the line was replaced by the 2008 standard of 865 yuan per year in 2000 prices (previously known as the low-income line). The minimum calorie threshold was kept fixed at 2,100 but the share of non-food allowance was increased. This line would be equivalent to $\$ 1.30$ per person per day in 2011 USD PPP terms (Chen and Ravallion, 2020). Finally, since 2012, under the 2010 standard households are considered poor if their annual per capita expenditure is below 2,300 yuan, expressed in 2010 values. This amount is considered sufficient to purchase a varied food basket of 2,100 calories, and nonfood items representing 47 percent of the total standard.

The 1978 and 2008 standards were significantly below the current international poverty line, whereas the 2010 standard has been generally close to the current $\$ 1.90$ international poverty line (2011 PPP), and is now slightly higher - equivalent to $\$ 2.30$ per person per day in $2011 \mathrm{PPP}$.

\section{Annex 2. Productivity growth in urban areas}

Rural and urban sectors were connected through forward and backward linkages in both labor and product markets. However, as the Chinese economy was becoming more market-oriented, some production activities in industries and services favored urban areas where transaction costs were lower than those in rural areas. For example, in 1980s and 2000s, the non-agricultural productivity boom was dominantly led by the urban areas (Figure A1).

Figure A1. Real earnings per worker growth in urban areas (in 2011 rural prices)

a. $1988-1995$

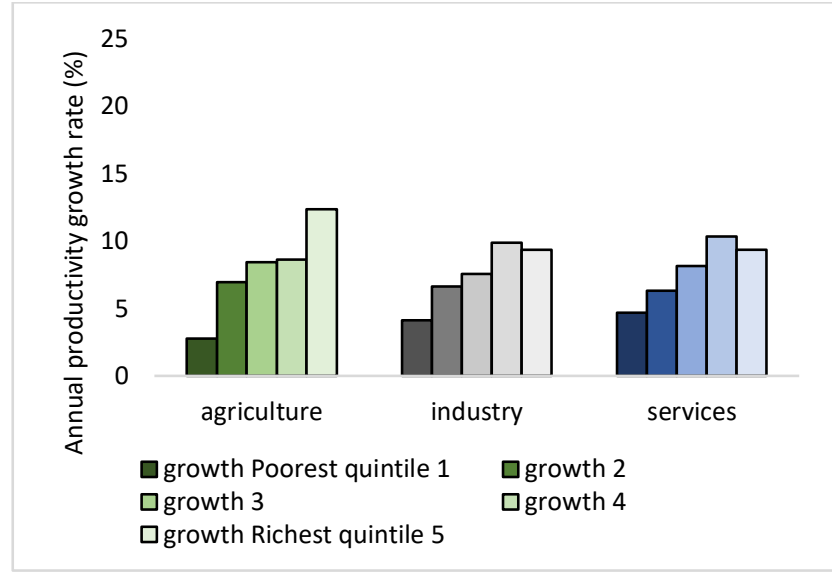

c. $2002-2007$ b. $1995-2002$

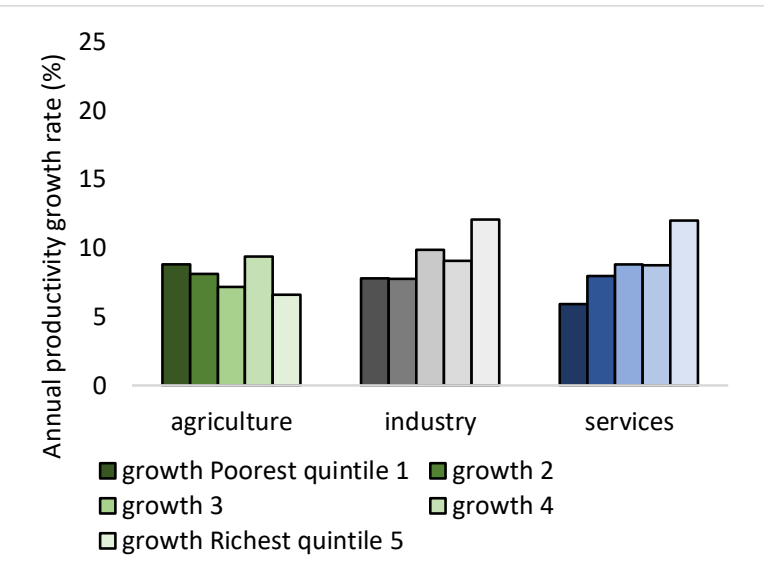

d. $2007-2013$ 

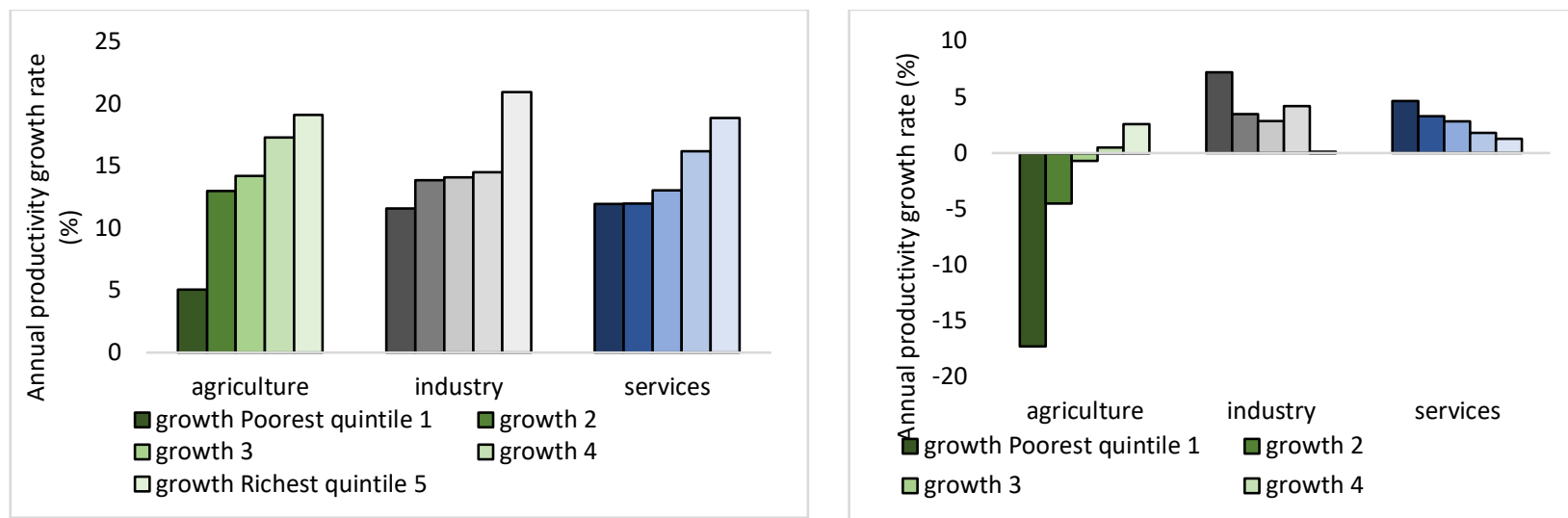

e. $2013-2018$

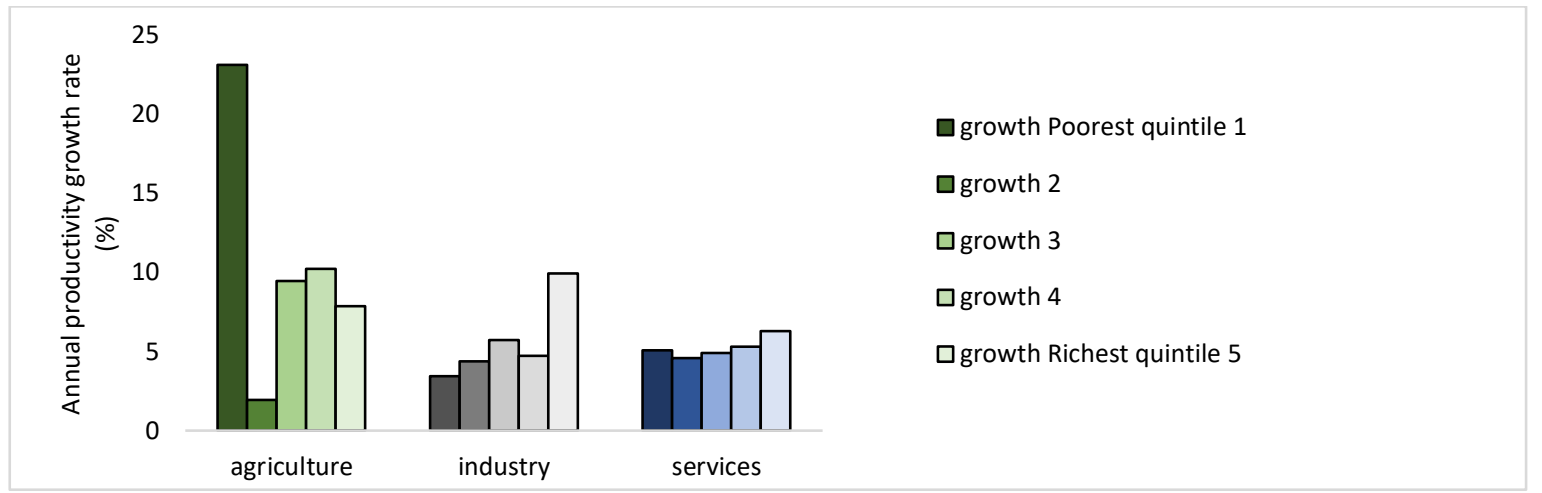

Source: Authors' calculation based on CHIP 1988, 1995, 2002, 2007, 2013. Quintiles are based on the urban distribution of per capita household income. 